Boletín de la Sociedad Geológica Mexicana

VOLUMEN 65, NÚM. 2, 2013, P. 481-496

\title{
Estratigrafía de la margen occidental de la cuenca San José del Cabo, Baja California Sur
}

\author{
Gabriela de Jesús Arreguín-Rodríguez ${ }^{1, *}$ y Tobias Schwennicke ${ }^{1}$ \\ ${ }^{1}$ Departamento Académico de Geológica Marina, Universidad Autónoma de Baja California Sur, Carretera al Sur Km 5.5, C.P. 23080, \\ La Paz, Baja California Sur \\ *gjarrreguin@gmail.com
}

\section{Resumen}

Un análisis estratigráfico efectuado en el arroyo San Dionisio, aportó datos sobre la evolución del margen occidental de la cuenca San José del Cabo, Baja California Sur. Esta cuenca forma parte de la Provincia Extensional del Golfo de California y su evolución inició en el Mioceno tardío. La cuenca, con estructura de medio graben, está limitada en su margen oeste por la falla lístrica San José del Cabo. En el arroyo San Dionisio están expuestas la falla marginal y tres formaciones estratigráficas divididas informalmente en dos unidades (inferior y superior), con orientación perpendicular a la margen de la cuenca y separadas por una discordancia angular. La unidad inferior está integrada por las formaciones Trinidad y Los Barriles, mientras que la unidad superior está constituida por la Formación El Chorro. En la parte oeste del arroyo, junto a la falla San José del Cabo y debido a la rotación a lo largo de la misma, aflora solamente la Formación El Chorro, la cual está compuesta por conglomerado y arenisca conglomerádica depositados en un ambiente de abanico aluvial. En afloramientos localizados más al este, arenisca conglomerádica y conglomerado de la Formación Los Barriles, depositados también en un ambiente de abanico aluvial, subyacen a la Formación El Chorro. Los sedimentos de ambas formaciones provienen del basamento expuesto en la sierra La Victoria. Aproximadamente $7 \mathrm{~km}$ al este de la falla marginal, se encuentra una interdigitación entre las formaciones Los Barriles y Trinidad; ésta última conformada por arenisca gruesa, arenisca arcillosa y lutita, de ambiente marino somero. La interdigitación muestra la contemporaneidad de ambas formaciones, probablemente en el Plioceno, además de que pone en evidencia la existencia de una zona costera con abanicos deltaicos durante el depósito de los sedimentos. En este abanico deltaico no se desarrollaron clinoformas, probablemente debido a la falta de espacio en una posición alejada de la falla marginal. La discordancia angular entre las secuencias superior e inferior marca un evento de reorganización de la cuenca; como consecuencia, se erosionó una parte de la unidad inferior en el Plioceno o inicios del Pleistoceno. Posteriormente, la rotación a lo largo de la falla confinó los depósitos aluviales de la Formación El Chorro a la parte occidental de la cuenca. Los depósitos más jóvenes de la Formación El Chorro cubren a la falla San José del Cabo y además muestran su disposición original, lo que sugiere la escasa o nula actividad de la misma desde finales del Pleistoceno.

Palabras clave: Cuenca San José del Cabo, falla San José del Cabo, Formación Trinidad, Formación Los Barriles, Formación El Chorro.

\begin{abstract}
A stratigraphical analysis performed at the Arroyo San Dionisio provided data on the evolution of the western margin of the San Jose del Cabo basin in Baja California, which evolution started in the late Miocene and is part of the Extensional Province of the Gulf of California. The half graben basin is bounded in its western margin by the listric fault of San José del Cabo. The marginal fault and three stratigraphic formations at the Arroyo San Dionisio are exposed perpendicularly to the basin margin, and were informally grouped into two sequences (lower and upper) separated by an angular unconformity. The lower sequence consists of the Trinidad and Los Barriles formations, while the upper sequence is constituted by the El Chorro Formation. In the western part of the arroyo, next
\end{abstract}


to the San José del Cabo fault and due to the rotation along it, only the El Chorro Formation is exposed. This formation is composed of conglomerate and conglomeratic sandstone deposited in an alluvial fan environment. In outcrops farther to the east, conglomeratic sandstone and conglomerate of the Los Barriles Formation, which reflect an alluvial fan depositional environment as well, underlie the El Chorro Formation. The sediments of both formations are derived from the basement exposed in the sierra La Victoria. The Los Barriles and Trinidad Formations interfinger approximately $7 \mathrm{~km}$ east to the marginal fault. The Trinidad Formation is composed of coarse sandstone, muddy sandstone, and mudstone of a shallow marine environment. The interfingering evidences the contemporaneity of both formations, probably in the Pliocene, and reveals the existence of a coastal area with a delta fan during deposition of the sediments. No clinoforms were developed in this delta fan deposits, probably due to the lack of space in an area far from the marginal fault. The angular unconformity between the lower and upper sequences probably reflects a basin reorganization resulting in the partial erosion of the lower sequence in the Pliocene or early Pleistocene. Subsequently, the rotation along the fault confined the alluvial deposits of the El Chorro Formation to the western part of the basin. The youngest deposits of the El Chorro Formation cover the San José del Cabo fault and also show their original sedimentary disposition, suggesting little or no activity along the fault since the late Pleistocene.

Keywords: San José del Cabo Basin, San José del Cabo Fault, Trinidad Formation, Los Barriles Formation, El Chorro Formation.

\section{Introducción}

Durante los últimos años la cuenca San José del Cabo, ubicada en el extremo sur de la península de Baja California (Figura 1), ha sido objeto de diversos estudios debido a su importancia en la evolución de la parte sur de la península y del golfo de California. La cuenca de San José del Cabo forma parte de la Provincia Extensional del Golfo de California (Stock y Hodges, 1989) y su evolución inició en el Mioceno tardío temprano (Fletcher et al., 2000). Los primeros en estudiar a detalle la estratigrafía del relleno sedimentario de la cuenca fueron Martínez-Gutiérrez y Sethi (1997) que además presentaron un modelo general de la evolución de la cuenca. Sin embargo, aún se tiene un conocimiento deficiente sobre la litoestratigrafía de las unidades dentro de la cuenca, las relaciones estratigráficas y las edades de las formaciones debido a la falta de estudios lito- y bioestratigráficos. En los últimos años se investigó de manera más específica la estratigrafía a lo largo de la margen oriental de la cuenca (McTeague, 2006; Piña-Arce, 2010). El propósito de este estudio, realizado a lo largo del arroyo San Dionisio y sus alrededores (Figura 2), en la margen occidental de la cuenca, es proporcionar datos que permitan comprender mejor la evolución de la cuenca San José del Cabo.

\section{Marco geológico}

La cuenca San José del Cabo tiene una estructura de medio graben (Martínez-Gutiérrez y Sethi, 1997; McTeague et al., 2005; McTeague, 2006; Schwennicke y Umhoefer, 2008, Piña-Arce, 2010; Busch et al., 2011) y su relleno sedimentario alcanza un espesor de $\sim 1.6 \mathrm{~km}$ en el centro de la cuenca (Busch et al., 2011). El origen de la cuenca ha sido relacionado con la apertura del golfo de California (McCloy, 1984; Martínez-Gutiérrez y Sethi, 1997; McTeague et al., 2005; Schwennicke y Umhoefer,
2008; Piña-Arce, 2010), la cual inició con la apertura de un rift ortogonal transformándose en uno oblicuo (Fletcher et al., 2007).

En ambos lados de la cuenca se encuentran rocas del basamento del Cretácico, que corresponden a las sierras La Victoria (al oeste) y La Trinidad (al este). En su porción oeste, la cuenca está limitada por la falla normal San José del Cabo (FSJC), la cual se inclina hacia el este. Fletcher et al. (2000) registraron una exhumación acelerada del basamento de 12-10 ma., la cual relacionaron con la activación de la FSJC. Dicha falla presenta periodos de reactivación durante el Cuaternario, evidenciados geomorfológicamente por la presencia de escarpes de falla y terrazas aluviales en valles fluviales en el bloque de piso (Gaitán-Morán, 1985). Busch et al. (2011) señalaron, a partir de un modelo gravimétrico, que en la cuenca San José del Cabo existen varias fallas sepultadas, formadas durante la etapa temprana de extensión, probablemente originadas antes que se creara la FSJC durante el Mioceno tardío, mientras que para la FSJC sugieren una edad pliocénica.

El relleno de la cuenca consiste de varias formaciones (Figura 1), las cuales fueron identificadas y definidas formalmente por Martínez-Gutiérrez y Sethi (1997). Estas unidades formales reemplazaron los nombres informales utilizados por autores anteriores (Hertlein, 1925; Hertlein y Jordan, 1927; Mina-Uhink, 1957; Pantoja-Alor y CarrilloBravo, 1966; McCloy, 1984; Smith, 1991). De acuerdo a Martínez-Gutiérrez y Sethi (1997) la Formación La Calera, la cual aflora en la margen este, marca el inicio de la sedimentación dentro de la cuenca. Se compone de 130 $\mathrm{m}$ de conglomerado rojizo y arenisca de origen fluvial, que probablemente se depositaron como resultado del inicio del fallamiento.

Los depósitos marinos de la Formación Trinidad marcan una transgresión marina en la parte central de la cuenca debido a subsidencia. Su espesor máximo se estima en $400 \mathrm{~m}$ y la unidad consiste de manera general en lutita laminada y no laminada, y arenisca (Martínez-Gutiérrez y 


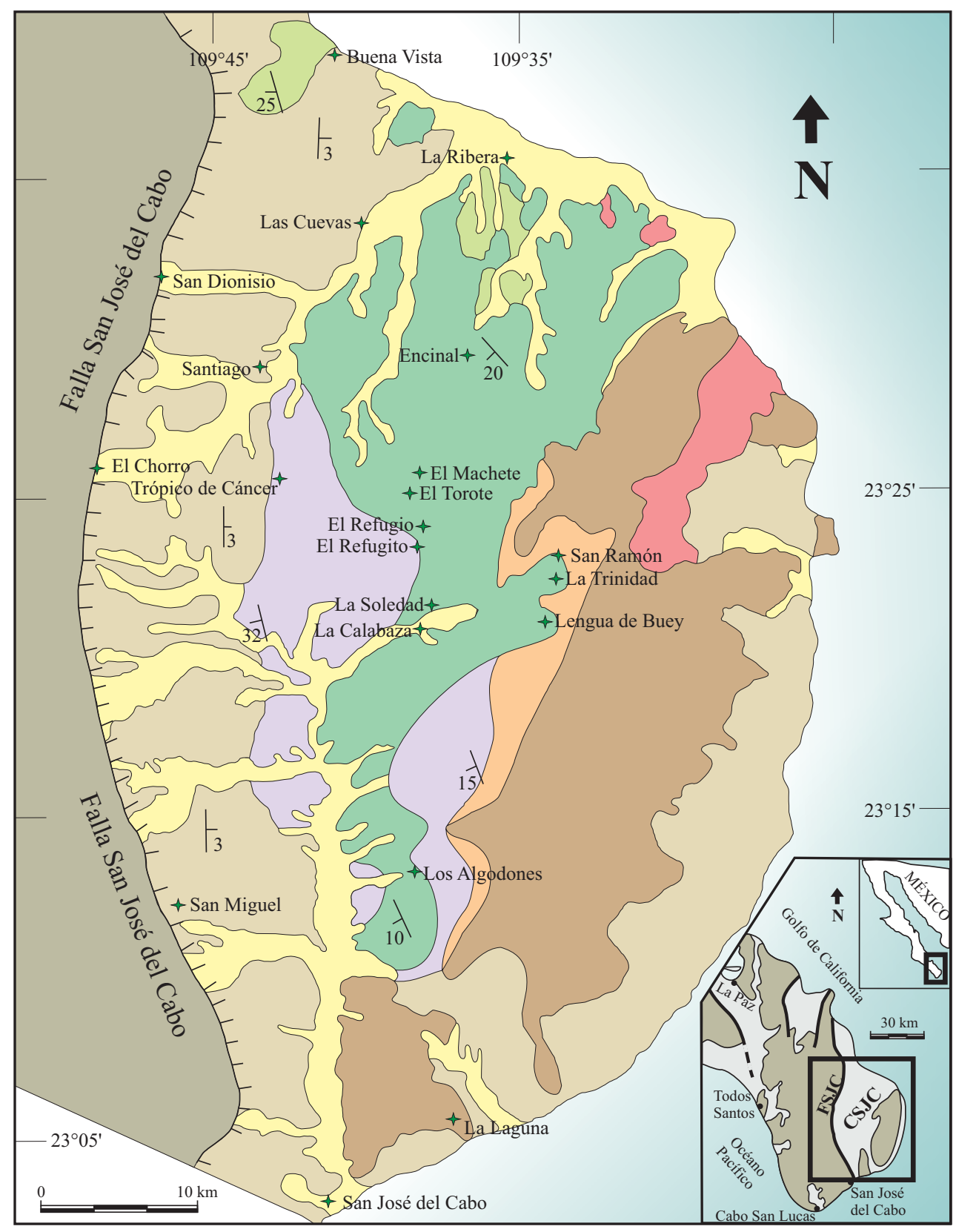

\section{$\underline{\text { Leyenda }}$}

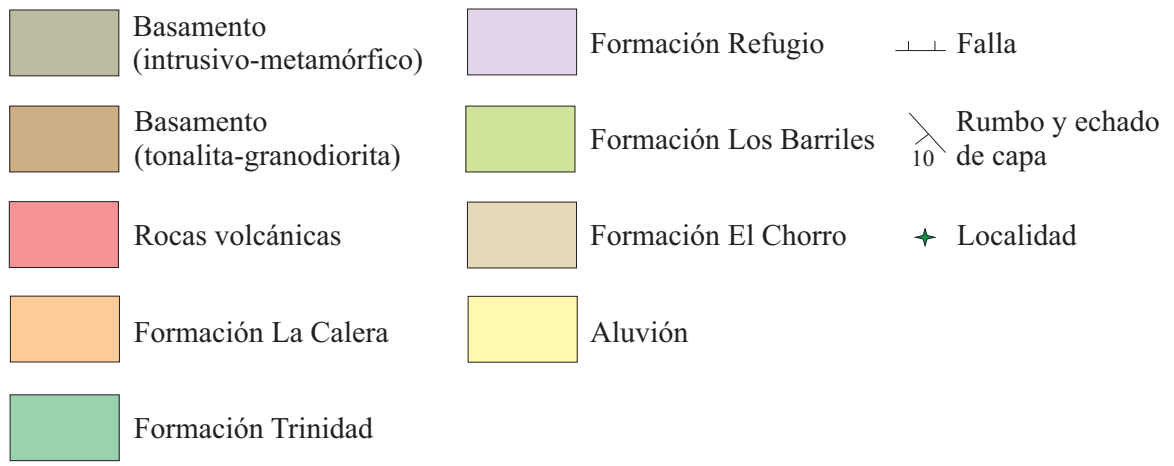

Figura 1. Localización de la cuenca San José del Cabo (CSJC) en el sur de la península de Baja California y mapa geológico de la CSJC (basado en Martínez-Gutiérrez y Sethi, 1997; McTeague, 2006 y datos no publicados de Tobias Schwennicke). 


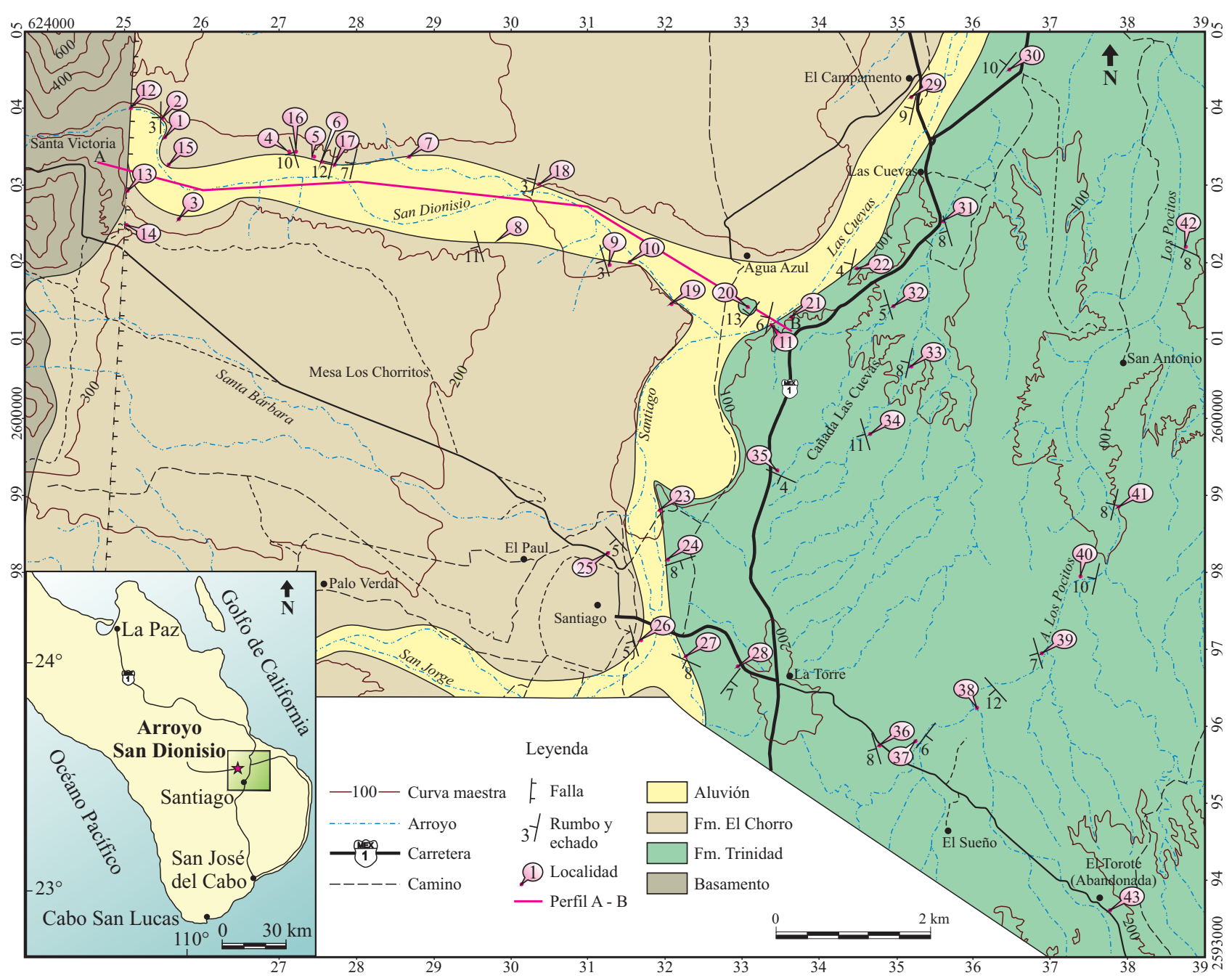

Figura 2. Mapa geológico a semi-detalle del área de estudio. Las localidades indican los sitios en los que se hizo descripción litológica y toma de datos estructurales, el levantamiento de columnas estratigráficas se hizo en las localidades 1 a 11.

Sethi, 1997). En zonas marginales de la cuenca el espesor de la Formación Trinidad es menor de 100 m (Piña-Arce, 2010) y los sedimentos marinos se interdigitan con depósitos terrestres (Schwennicke y Umhoefer, 2008). Las edades propuestas, con base en el registro fósil en diferentes localidades, varían de Mioceno tardío a Plioceno tardío (Hertlein y Jordan, 1927; Pantoja-Alor y Carrillo-Bravo, 1966; McCloy, 1984; Pérez-Guzmán, 1985; TrápagaMartínez, 1985; Rodríguez-Quintana y Segura-Vernis, 1991; Carreño y Segura-Vernis, 1991; Carreño, 1992; MolinaCruz, 1994; Ibaraki, 1997; McTeague, 2006; Carreño y Smith, 2007; Piña-Arce, 2010).

La Formación Refugio es la unidad marina más joven, compuesta principalmente por arenisca bioclástica de grano grueso. Su espesor alcanza $380 \mathrm{~m}$ (Martínez-Gutiérrez y Sethi, 1997) y se interdigita con la Formación Trinidad (Piña-Arce, 2010). La edad propuesta para la Formación Refugio (llamada inicialmente Formación Salada) es Plioceno, con base en el registro fósil de moluscos marinos
(Hertlein, 1925, 1966; McCloy, 1984; Smith, 1991; PérezLópez, 2002).

La Formación Los Barriles tiene un espesor de 1650 $m$ en el arroyo Buenos Aires, localizado en el norte de la cuenca (Martínez-Gutiérrez y Sethi, 1997). Esta unidad está conformada por depósitos conglomerádicos $\mathrm{y}$ arenisca gruesa, los cuales se acumularon en ambientes de abanico aluvial de alto gradiente, debido a la actividad contemporánea de la falla San José del Cabo. No hay evidencias claras para determinar la edad de la Formación Los Barriles; sin embargo, Martínez-Gutiérrez y Sethi (1997) estimaron una edad de Plioceno tardío a Pleistoceno temprano. Según estos autores, la unidad sobreyace discordantemente a la Formación Trinidad y se interdigita con la Formación Refugio.

Por último, la Formación El Chorro se compone de arenisca de grano grueso y conglomerado de origen fluvial. Según Martínez-Gutiérrez y Sethi (1997) su espesor máximo es de $150 \mathrm{~m}$, el cual alcanza a lo largo de la margen oeste 
de la cuenca. Estos autores propusieron una edad de Pleistoceno Tardío a Holoceno temprano.

Las formaciones estratigráficas dentro de la cuenca tienen espesores diferentes dependiendo de la localidad y son diacrónicas; aunque algunos autores señalaron la contemporaneidad parcial entre algunas unidades (McTeague, 2006; Schwennicke y Umhoefer, 2008; PiñaArce, 2010; Arreguín-Rodríguez, 2010). Martínez-Gutiérrez y Sethi (1997) fueron los primeros, quizás, en reconocer la complejidad en espacio y tiempo de las relaciones estratigráficas de la cuenca, como lo muestran en su modelo de depósito, aunque en su tabla estratigráfica no señalan tal complejidad. Inicialmente los estudios estratigráficos a detalle se enfocaron en la margen oriental de la cuenca (McTeague, 2006; Schwennicke y Umhoefer, 2008; PiñaArce, 2010). Más recientemente se investigó a mayor detalle también el lado occidental (Geoffroy y Pronost, 2009; Arreguín-Rodríguez, 2010; Masini et al., 2010). Geoffroy y Pronost (2009) estudiaron el extremo noroeste de la cuenca (área no considerada en el trabajo de Martínez-Gutiérrez y Sethi, 1997) y reconocieron una falla de despegue contemporánea a las formaciones Refugio y Los Barriles, a la que consideraron independiente de la falla San José del Cabo. Además, sugirieron la existencia de una estructura roll-over originada por fallamiento. Según estos autores, la falla de despegue quedó inactiva después del depósito de la Formación Los Barriles, ya que esta unidad y la falla están cubiertas discordantemente por la Formación El Chorro. Arreguín-Rodríguez (2010) señaló la interdigitación y por lo tanto, la contemporaneidad entre las formaciones Los Barriles y Trinidad, modificando lo anteriormente propuesto por Martínez-Gutiérrez y Sethi (1997).

\section{Estratigrafía}

Se levantaron varias columnas estratigráficas a lo largo del arroyo San Dionisio (Figura 3), donde fueron reconocidas dos unidades estratigráficas informales: inferior y superior (Figura 4). En los afloramientos predomina la unidad superior. La unidad inferior está conformada por una transición lateral de capas de conglomerado y arenisca de ambiente fluvial hacia estratos de arenisca y lutita de origen marino, que corresponden a las formaciones Los Barriles y Trinidad respectivamente, y las cuales se interdigitan. La unidad superior consiste de capas de arenisca y conglomerado de origen fluvial de la Formación El Chorro (Figura 5).

El contacto entre las rocas de ambas unidades es discordante, ya que las capas de la unidad inferior presentan una mayor inclinación que las de la unidad superior; este contacto es marcadamente erosivo. En el área de estudio, la inclinación de las rocas de la unidad inferior en promedio es de $8^{\circ}$, con un rango entre $3^{\circ}$ y $12^{\circ}$; la dirección de inclinación varía de SW a NW. En la unidad superior la inclinación es de $3^{\circ}$ al W, junto al lecho del arroyo y cerca de la falla
San José del Cabo; hacia la cima (mesa Los Chorritos) la inclinación cambia al E, paralelamente a la superficie de la mesa, lo que al parecer corresponde a la disposición original, sin efecto de rotación. Igualmente, en la parte central y este del arroyo San Dionisio y por lo tanto más alejado de la falla San José del Cabo, las capas de la Formación El Chorro se inclinan con $1^{\circ}$ al E.

Las rocas de la unidad inferior no afloran junto a la falla San José del Cabo, sino que aparecen por primera vez aproximadamente a $2 \mathrm{~km}$ al este de la misma y su espesor aumenta en dicha dirección (al este). Por el contrario, la unidad superior tiene su mayor espesor en la región más cercana a la falla San José del Cabo, donde llega a $150 \mathrm{~m}$ aproximadamente (Figura 5).

\subsection{Unidad inferior}

La unidad inferior incluye depósitos fluviales de la Formación Los Barriles (Figura 6) y sedimentos marinos de la Formación Trinidad. En la Formación Los Barriles, que aflora en la parte cercana al bloque de techo de la falla San José del Cabo, se identificaron dos facies principales (Tabla 1): arenisca conglomerádica (LB1) y en menor proporción conglomerado (LB2). El sedimento proviene del basamento ígneo-metamórfico expuesto al oeste de la falla San José del Cabo, dando un tono claro a estos depósitos. Los porcentajes de la proporción entre conglomerado y arenisca conglomerádica difieren de los depósitos de esta formación en su localidad tipo en el arroyo Buenos Aires, que suelen ser dominados por conglomerado (MartínezGutiérrez y Sethi, 1997).

La Formación Los Barriles fue depositada en un ambiente de abanico aluvial de alto gradiente (MartínezGutiérrez y Sethi, 1997) en un clima desértico. En su porción proximal es posible identificar varias subfacies (LB1-a, b, c y LB2-a, b, c: Tabla 1) que reflejan la predominancia de flujos de escombro y de avenida. En la parte distal del abanico aluvial se encuentran depósitos de acreción lateral (subfacies LB1-d), indicando mayor incidencia de corrientes trenzadas (Arreguín-Rodríguez, 2010).

Hacia el este, la interdigitación con la Formación Trinidad (Figura 7), se compone de tres facies (Tabla 1): arenisca arcillosa (T1), arenisca gruesa (T2) (Figura 8) y lutita (T3) (Figura 9). Mientras que las facies T1 y T2 están ampliamente expuestas formando una alternancia (columna 11), la facies T3 únicamente aflora en el extremo este del arroyo (localidad 10, Figura 2), intercalándose entre depósitos aluviales (columna 10, capa 5). La facies T1 refleja condiciones marinas de energía moderada y oxigenada, favorable para la colonización por organismos (Figuras 8 y 10). Las características de las capas de la facies $T 2$ indican que son producto de flujos gravitacionales esporádicos (Tabla 1). Sin embargo, carecen de rasgos más específicos para clasificarlos como capas producidas por tormentas (tempestites), turbiditas o turbiditas de plataforma (shelf turbidites, Myrow y Southard, 1996; Einsele y Seilacher, 
1991). La facies T3 se depositó como consecuencia de etapas de mayor subsidencia en un ambiente de planicie de marea, cubriendo parte de los sedimentos aluviales (Formación Los Barriles).

Además, en la Formación Trinidad se encuentran deformaciones sinsedimentarias de hasta $15 \mathrm{~m}$ de espesor (Figura 11, localidad 11), que reflejan procesos de deslizamiento (slumping) y plegamiento. El sedimento que conforma el deslizamiento es arenisca gruesa, parcialmente conglomerádica con gránulos dispersos y escasos clastos con tamaño de hasta $10 \mathrm{~cm}$. A corta distancia, las rocas generalmente parecen homogéneas hasta masivas; sin embargo, a una distancia mayor se notan las deformaciones irregulares producidas por el deslizamiento submarino.

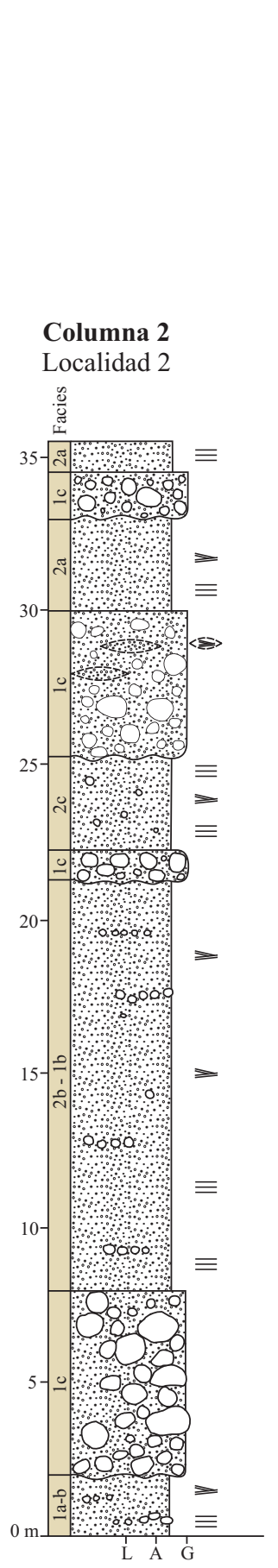

Simbología

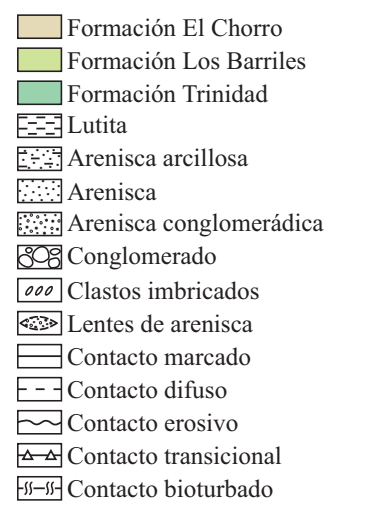
$\equiv$ Estratificación paralela
$=$ Laminación paralela
$\equiv$ Estratificación subparalela
E Laminación subparalela
\$ Estratificación cruzada
mm Laminación cruzada
$\approx$ Laminación ondulada
$\approx$ Estratificación flaser
Estratificación lenticular
$\triangle$ Gradación normal
凤 Deslizamiento y plegamiento
$\triangle$ Diente
\& Bioturbación
- Madrigueras
A Ophiomorpha isp.

\section{Columna 4}

Localidad 4

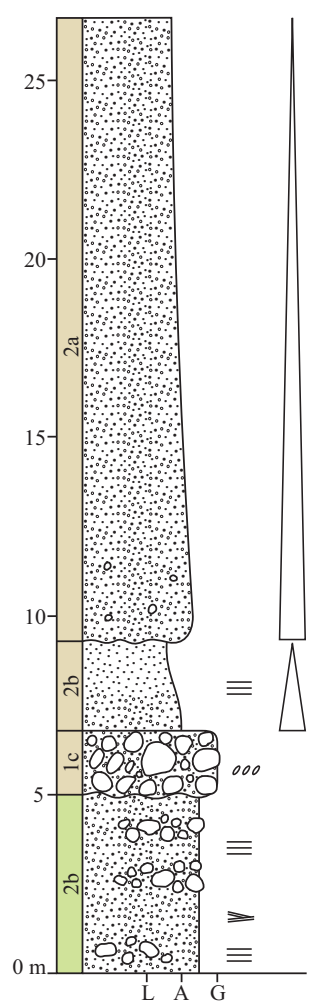

Columna 10

Localidad 10

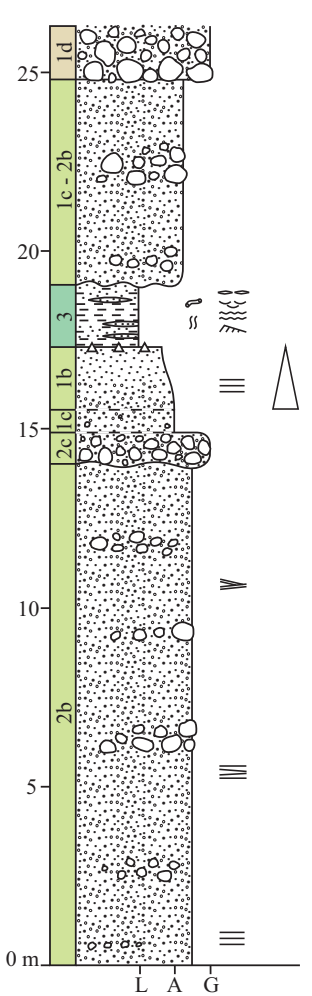

Columna 11

Localidad 11

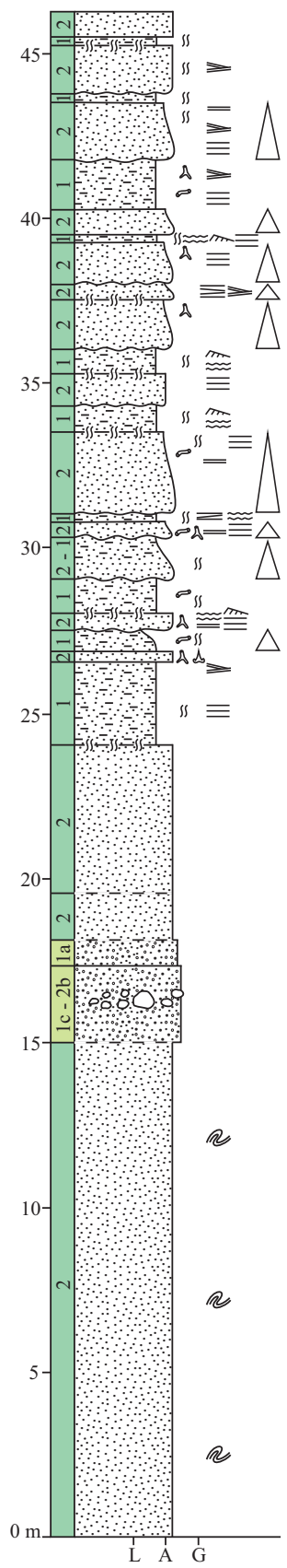

Figura 3. Columnas estratigráficas generalizadas levantadas a lo largo del arroyo San Dionisio. Las letras y números de facies hacen referencia a la facies y/o subfacies correspondiente según la formación estratigráfica. Abreviaturas: L-limo, A-arena, G-grava. 
La interdigitación entre los depósitos de la Formación Los Barriles (abanico aluvial) y Formación Trinidad (mar somero) corresponde a un ambiente costero deltaico. Postma (1990) reconoció varios tipos de abanico deltaicos en los que el sistema fluvial alimentador aporta sedimento grueso debido a un gradiente marcado en la porción fluvial (que en este caso corresponde a la Formación Los Barriles), tales como el tipo Hjulström (aguas someras), el clásico tipo Gilbert con grupos de capas frontales (foresets beds) y Gilbert de aguas profundas.

En el área del arroyo San Dionisio no se observaron grupos de capas frontales (foresets beds), lo que caracteriza a deltas de aguas someras. La presencia de los depósitos de la facies T2 y estructuras de deslizamiento (slump) suelen indicar que el gradiente fue suficientemente marcado para inducir procesos gravitacionales; no obstante este tipo de procesos pueden darse con inclinaciones mínimas en

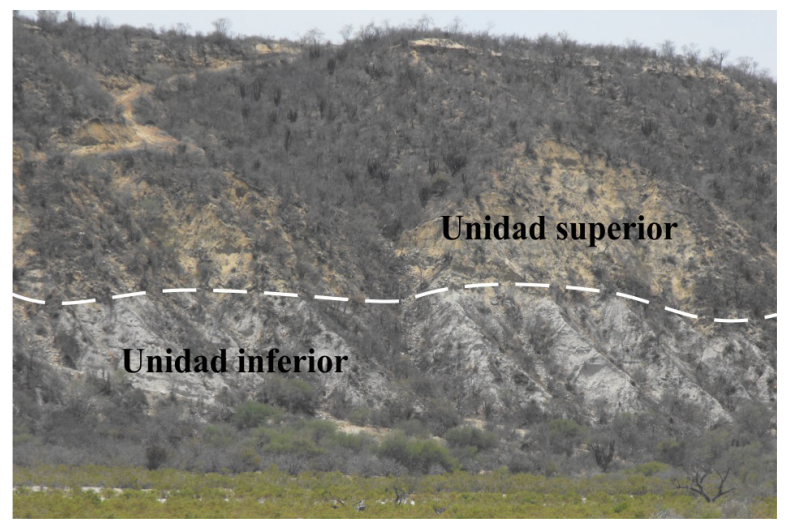

Figura 4. Contacto entre las unidades superior e inferior sobre el arroyo San Dionisio (localidad 8) ambientes acuáticos (Lewis, 1971; Field et al., 1982; Niemi y Ben-Avraham, 1994; Gibert et al., 2005), como resultado de terremotos (Field et al., 1982; Dorsey et al., 1997) o por tormentas (Xu et al., 2009). Sin embargo, hacia el este del área de estudio predominan los depósitos marinos de aguas más profundas con depósitos diatomíticos, por ejemplo en El Torote (Figura 2, localidad 43), lo que señala la presencia de un fondo marino con cierto gradiente.

A pesar de estas condiciones generales, localmente (al sureste del arroyo San Dionisio) se observan también secuencias deltaicas con grupos de capas frontales (foresets beds), con espesores de varios metros intercalados en depósitos marinos formados por encima del nivel base de oleaje (Figuras 2 y 12, localidad 28 y 37). Los depósitos de la localidad 28 probablemente corresponden a un periodo de poca actividad de la FSJC, lo que permitió el avance de los sedimentos costeros hacia el centro de la cuenca (Dorsey

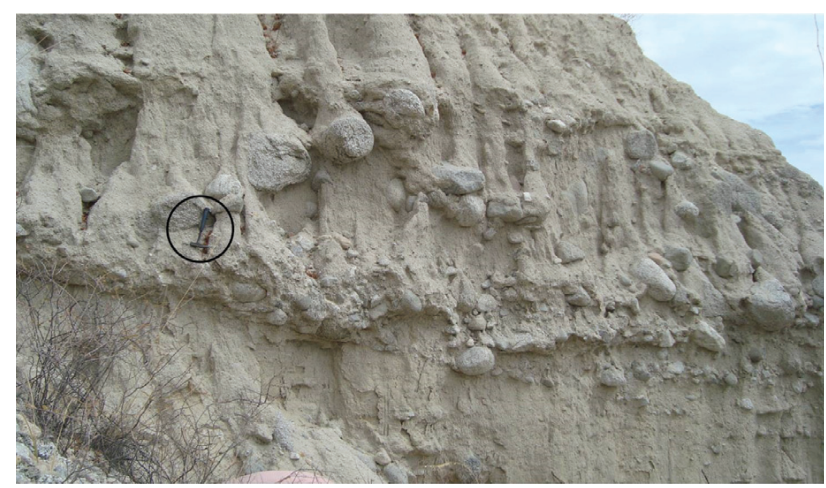

Figura 6. Arenisca conglomerádica y conglomerado de la Formación Los Barriles en el arroyo San Dionisio (localidad 7). En el círculo negro, martillo de geólogo como escala de referencia.

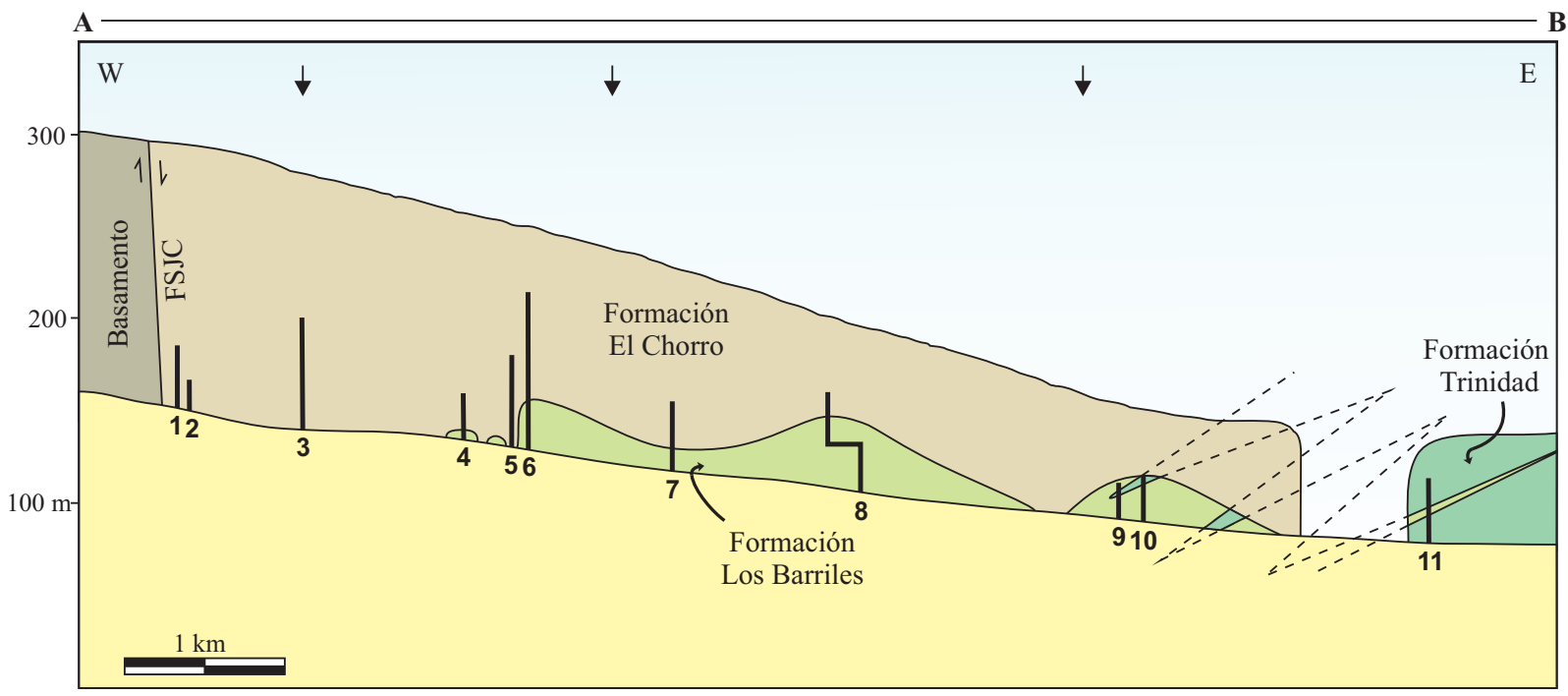

Figura 5. Perfil A-B, mostrado en la Figura 2 a lo largo del arroyo San Dionisio, con exageración vertical factor 15, que señala la distribución de las formaciones estratigráficas. Las flechas en la parte superior indican los cambios de dirección en el perfil. Las líneas negras numeradas del 1-11 señalan las columnas levantadas y las líneas punteadas hacen referencia a la zona de interdigitación. 
Tabla 1. Clasificación de facies y subfacies de la secuencia inferior en el arroyo San Dionisio.

\begin{tabular}{|c|c|c|c|}
\hline & Facies / Subfacies & Descripción & Interpretación \\
\hline \multirow{12}{*}{ 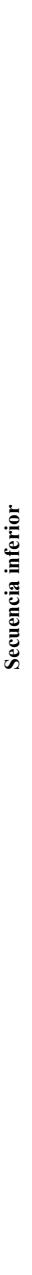 } & Facies $L B 1$ & $\begin{array}{l}\text { Arenisca conglomerádica mal clasificada. Predominio de grava sobre gránulos. Algunos } \\
\text { clastos miden } 20 \mathrm{~cm} \text { de largo. Estratificación paralela y cruzada. Bioturbación escasa a } \\
\text { moderada. }\end{array}$ & \\
\hline & $\begin{array}{l}\text { Subfacies } L B 1-a \\
\text { Arenisca conglomerádica }\end{array}$ & $\begin{array}{l}\text { Espesor de capas generalmente menor de } 1 \mathrm{~m} \text {. Arena mal clasificada con pocos gránulos } \\
\text { muy finos. La estratificación es difícil de identificar; localmente es paralela y muy difusa } \\
\text { Bioturbación difusa. Contactos marcados a difusos. }\end{array}$ & $\begin{array}{l}\text { Depósitos de flujos de avenida dentro de un sistema de abanico } \\
\text { aluvial. }\end{array}$ \\
\hline & $\begin{array}{l}\text { Subfacies } L B 1-b \\
\text { Arenisca conglomerádica }\end{array}$ & $\begin{array}{l}\text { Espesor de capas hasta } 2.20 \mathrm{~m} \text {. Internamente diferenciada entre fracciones finas y gruesas, } \\
\text { en láminas o por gradación. Estratificación paralela, poca estratificación subparalela y } \\
\text { cruzada plana de bajo ángulo. Contactos difusos o transicionales. }\end{array}$ & $\begin{array}{l}\text { Flujos de avenida con régimen de flujo superior asociados a un } \\
\text { ambiente de abanico aluvial. }\end{array}$ \\
\hline & $\begin{array}{l}\text { Subfacies } L B 1-c \\
\text { Arenisca conglomerádica }\end{array}$ & $\begin{array}{l}\text { Espesor de capas hasta } 20.50 \mathrm{~m} \text {. Arena mal clasificada con clastos dispersos. } \\
\text { Estratificación paralela, semiparalela y cruzada plana de bajo ángulo. Contactos marcados, } \\
\text { transicionales, erosivos o difusos. }\end{array}$ & $\begin{array}{l}\text { Flujos de avenida con variaciones de energía dentro del abanico } \\
\text { aluvial. }\end{array}$ \\
\hline & $\begin{array}{l}\text { Subfacies } L B 1-d \\
\text { Arenisca conglomerádica }\end{array}$ & $\begin{array}{l}\text { Espesor de capas hasta } 1.5 \mathrm{~m} \text {. Arena mal clasificada, clastos con diámetros hasta } 5 \mathrm{~cm} \text {, } \\
\text { dispersos o en lentes. Estratificación cruzada plana de escala media a grande, poca } \\
\text { estratificación paralela. Contactos difusos o bioturbados. }\end{array}$ & $\begin{array}{l}\text { Barras transversales, laterales y/o longitudinales en canales de } \\
\text { corrientes trenzadas relacionados al sistema de abanico aluvial. }\end{array}$ \\
\hline & Facies $L B 2$ & Conglomerado soportado por clastos y/o matriz. & \\
\hline & $\begin{array}{l}\text { Subfacies } L B 2-a \\
\text { Conglomerado }\end{array}$ & Horizontes o agrupaciones de hasta $20 \mathrm{~cm}$ de espesor. Tamaño de los clastos hasta $20 \mathrm{~cm}$. & $\begin{array}{l}\text { Depósitos remanentes tipo lag asociados a un ambiente de } \\
\text { abanico aluvial. }\end{array}$ \\
\hline & $\begin{array}{l}\text { Subfacies } L B 2-b \\
\text { Conglomerado }\end{array}$ & $\begin{array}{l}\text { Lentes y/o agrupaciones de clastos gruesos. Espesor hasta } 1.90 \mathrm{~m} \text {. Tamaño común de } \\
\text { clastos hasta } 50 \mathrm{~cm} .\end{array}$ & $\begin{array}{l}\text { Depósitos en lentes, localmente relacionado con relleno de } \\
\text { canales en abanicos aluviales. }\end{array}$ \\
\hline & $\begin{array}{l}\text { Subfacies } L B 2-c \\
\text { Conglomerado }\end{array}$ & $\begin{array}{l}\text { Capas con espesores de } 0.90 \text { a } 4 \mathrm{~m} \text {. Soportado por clastos y matriz. Tamaño común de los } \\
\text { clastos hasta } 30 \mathrm{~cm} \text {. Arreglo interno caótico. Contactos erosivos, transicionales o difusos. }\end{array}$ & $\begin{array}{l}\text { Depósitos de flujos de escombro no cohesivos dentro de los } \\
\text { abanicos aluviales. }\end{array}$ \\
\hline & Facies T1 & $\begin{array}{l}\text { Espesor de capas de } 0.07 \text { a } 2.10 \mathrm{~m} \text {. Arenisca mal clasificada, arcillosa y de textura } \\
\text { homogénea, dominando arena fina-media. Gránulos escasos. Laminación cruzada, } \\
\text { ondulada y subparalela. Estratificación paralela y cruzada de bajo ángulo. Escasos } \\
\text { fragmentos de conchas. La bioturbación es regular a abundante con presencia de } \\
\text { Ophiomorpha isp. y Skolithos isp. Contactos difusos, bioturbados, erosivos o marcados. }\end{array}$ & $\begin{array}{l}\text { Marino somero con condiciones energéticas variando entre } \\
\text { tranquilo y regular; temporalmente pudo haber alta energía. } \\
\text { Condiciones favorables para colonización del fondo marino y } \\
\text { retrabajo fisico no muy intenso. Los depósitos pertenecen a un } \\
\text { sistema de abanico deltaico. No hay evidencias de playa frontal } \\
\text { superior de alta energía o anteplaya. }\end{array}$ \\
\hline & Facies $T 2$ & $\begin{array}{l}\text { Espesor de capas hasta } 1.60 \mathrm{~m} \text {. Arenisca gruesa mal clasificada, escasos gránulos y } \\
\text { excepcionalmente clastos aislados de mayor tamaño, de hasta } 5 \mathrm{~cm} \text {. Textura homogénea o } \\
\text { gradación normal. Laminación paralela, cruzada y ondulada. Estatificación paralela, } \\
\text { subparalela y cruzada plana de bajo ángulo. Bioturbación común hasta ausente, } \\
\text { concentrada en la parte superior. Escasos intraclastos arcillosos en la parte basal. } \\
\text { Icnofósiles: Ophiomorpha isp. Contactos erosivos, bioturbados, difusos o marcados. }\end{array}$ & $\begin{array}{l}\text { Flujos gravitacionales dentro de un ambiente de abanico deltaico. } \\
\text { Las capas exhiben pocas características típicas para distinguirlas } \\
\text { entre capas producidas por tormentas (tempestites) o turbiditas. }\end{array}$ \\
\hline & Facies T3 & $\begin{array}{l}\text { Espesor de capas hasta } 1.50 \mathrm{~m} \text {. Arenisca fina arcillosa a lutita. Laminación cruzada y } \\
\text { ondulada. Estratificación paralela, flaser y lenticular. Bioturbación regular y presencia de } \\
\text { madrigueras. Contactos erosivos o difusos. }\end{array}$ & Depósitos de planicie de marea. \\
\hline
\end{tabular}

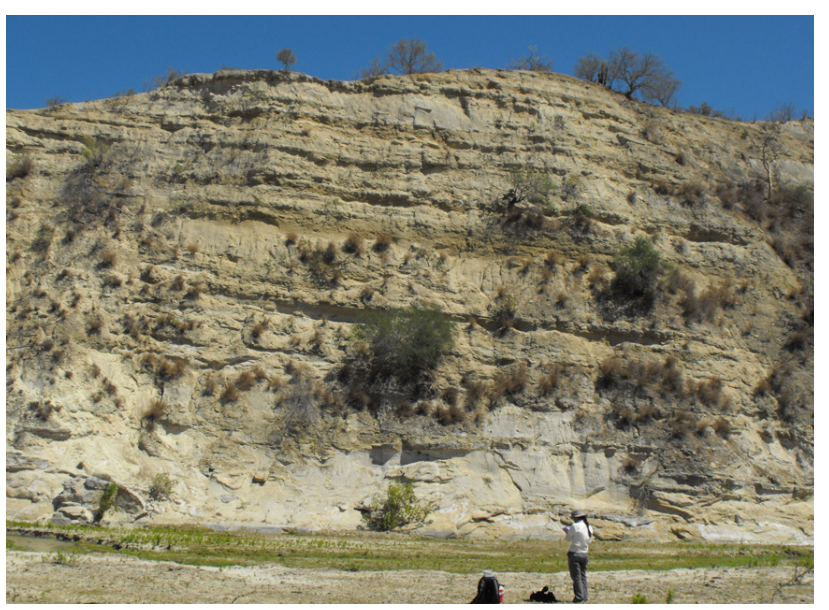

Figura 7. Afloramiento de la Formación Trinidad en la localidad 11 sobre el arroyo Las Cuevas (Figura 3: columna 11).

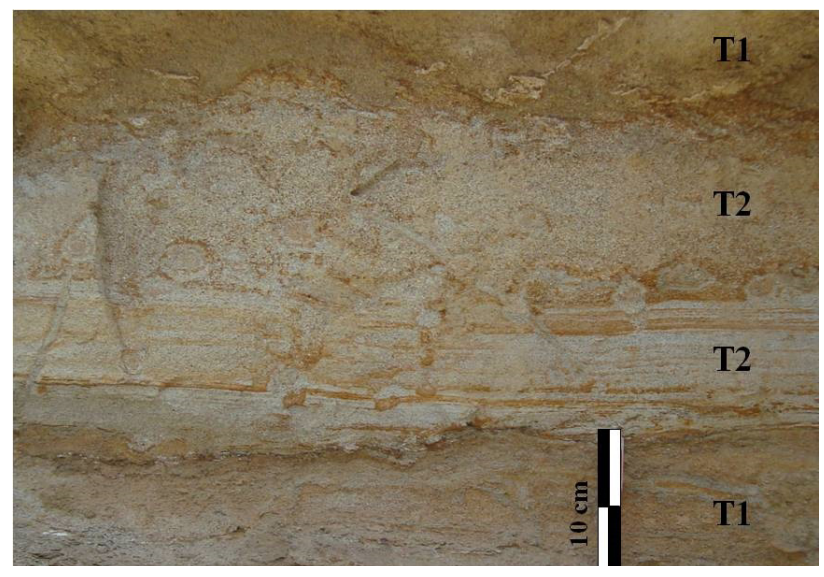

Figura 8. Facies T1 y T2 de la Formación Trinidad sobre el arroyo Las Cuevas (localidad 11). La facies T1 consiste en arenisca arcillosa y la facies T2 incluye una capa de arenisca mediana-gruesa y otra de arenisca muy gruesa. 
y Umhoefer, 2000).

\subsection{Unidad superior}

En la unidad superior, que corresponde a la Formación El Chorro (Figura 13), se distinguen dos facies principales:

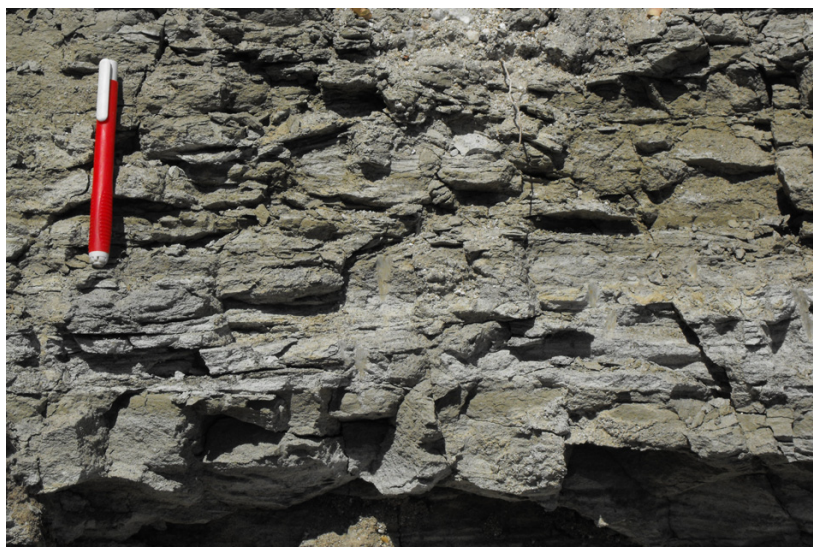

Figura 9. Lutita de la Facies T3 de la Formación Trinidad en la localidad 10 en el arroyo San Dionisio (Figura 3: columna 10). El borrador mide $13 \mathrm{~cm}$. conglomerado (EC1) y arenisca conglomerádica (EC2), ambas de composición ígneo-metamórfica generalmente de color café (Tabla 2), proveniente del basamento. La facies dominante es la EC1 con un $57 \%$ y la facies EC2 abarca el $43 \%$ restante con respecto a las columnas medidas. Estas columnas, aunque no abarcan todo el espesor de la

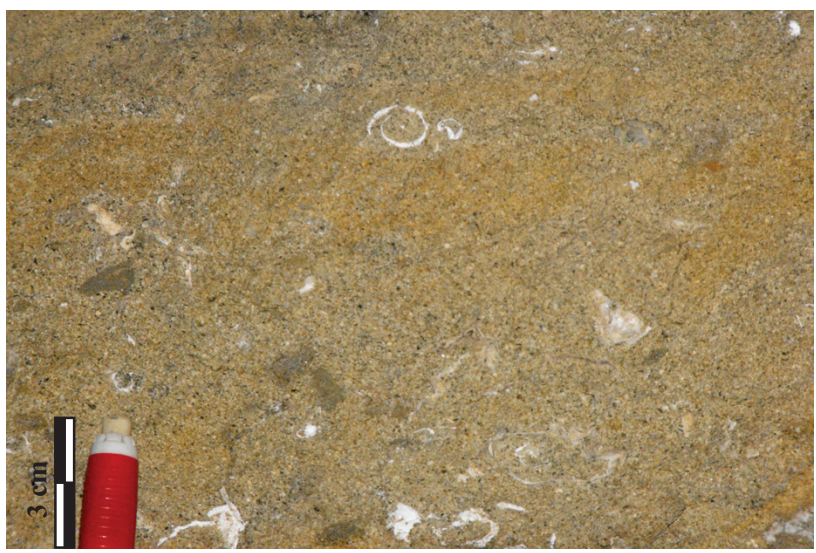

Figura 10. Bivalvos en la facies T1 de la Formación Trinidad en el arroyo Las Cuevas (localidad 21). El sedimento está intensamente bioturbado.

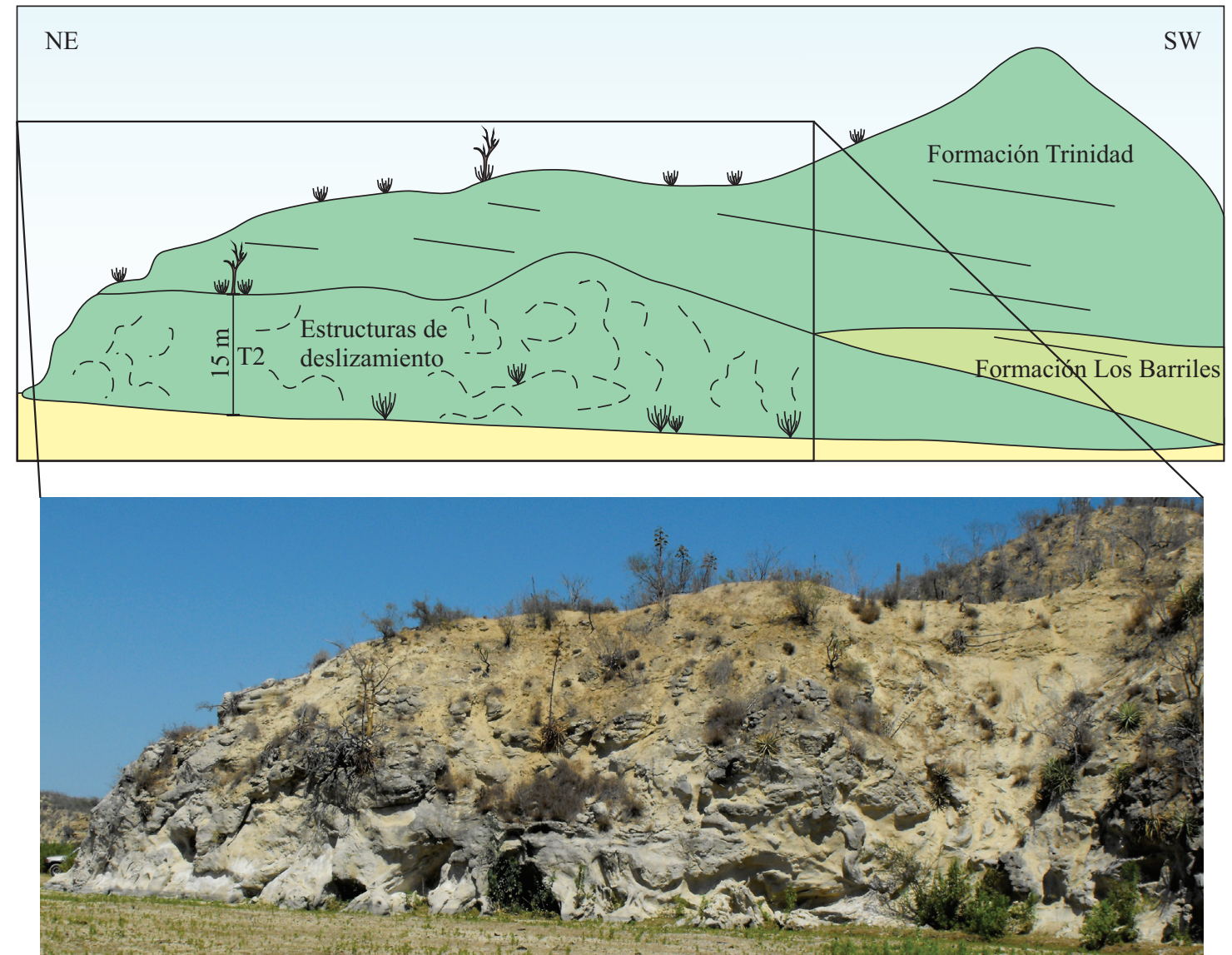

Figura 11. Estructuras por deslizamiento (slump) en la facies T2 de la Formación Trinidad en el arroyo Las Cuevas (Figura 3, localidad 11, columna 11). 

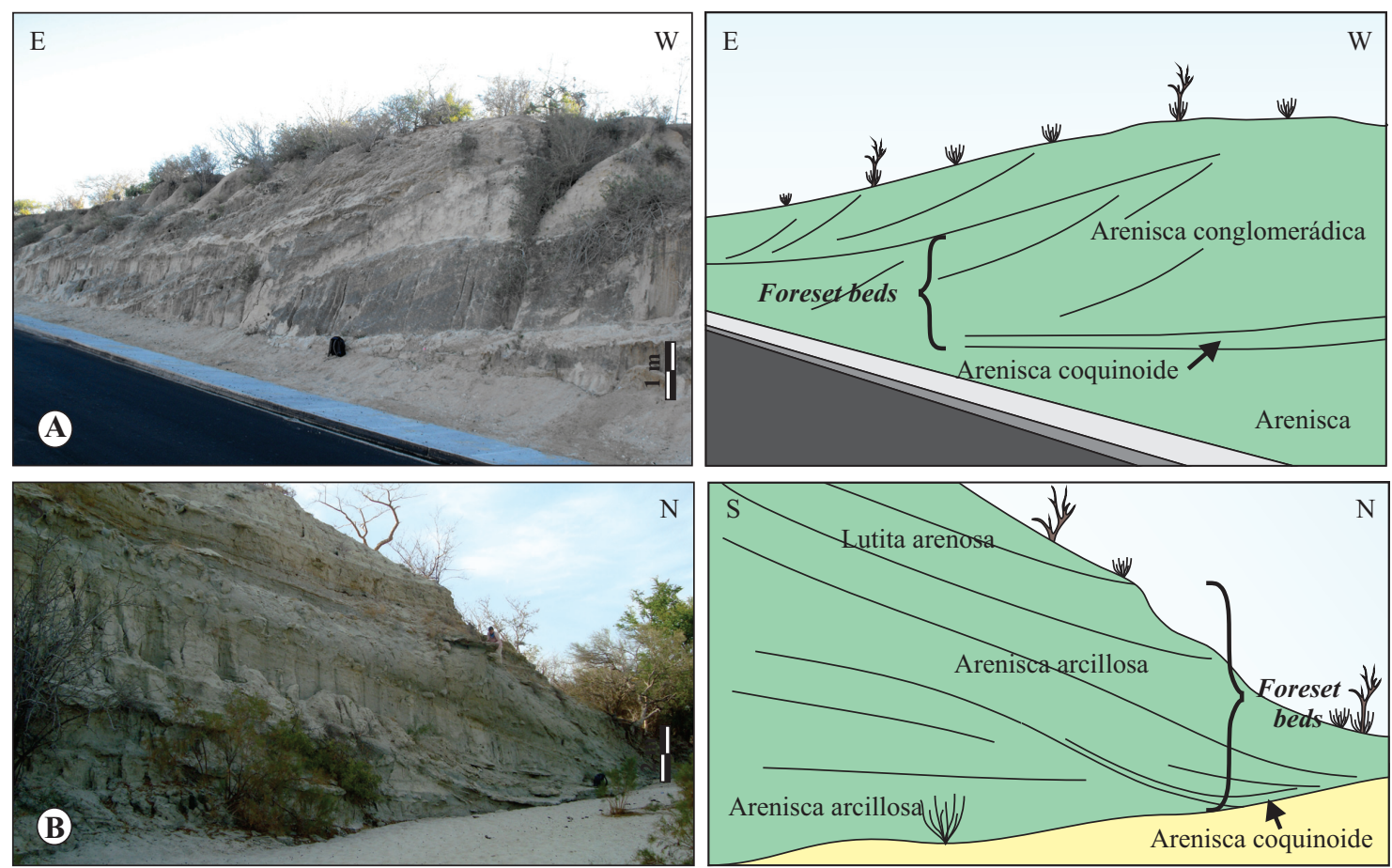

Figura 12. Grupo de capas frontales (foreset beds) de origen deltaico en la Formación Trinidad compuestos por: A) arenisca conglomerádica y arenisca coquinoide (localidad 28), B) arenisca arcillosa y arenisca coquinoide (Figura 2, localidad 37).

Formación El Chorro, sí son representativas, ya que no se observó ningún cambio en la litología hacia la parte superior (Arreguín-Rodríguez, 2010).

La Formación El Chorro fue depositada en un ambiente de abanico aluvial y es posible identificar varias facies y subfacies (Tabla 2). Estas facies señalan que en la parte proximal del abanico (oeste del arroyo San Dionisio) predominan depósitos formados por flujos de escombro y de avenida. Además, ocurren depósitos formados como barras arenosas y gravosas. Hacia la parte distal (este del arroyo San Dionisio) se encuentran con mayor frecuencia los depósitos de acreción lateral y canales, lo cual refleja el desarrollo de corrientes trenzadas. En conclusión, el ambiente sedimentario de la Formación El Chorro, varía de abanicos dominados por flujos de escombro y avenida a abanicos dominados por corrientes trenzadas, este ambiente es similar al de los depósitos de la Formación Los Barriles. En general, el depósito de la Formación El Chorro ocurrió bajo condiciones desérticas y los cambios laterales de facies reflejan la reducción del gradiente.

La parte inferior de la Formación El Chorro, la cual aflora sobre el arroyo San Dionisio, está en contacto con el basamento por la falla SJC. Sin embargo, en la mesa Los Chorritos la parte más joven de la Formación El Chorro cubre a la falla SJC, indicando que ésta estuvo inactiva durante el depósito de esta porción más joven de la formación (Figuras 2 y 14).

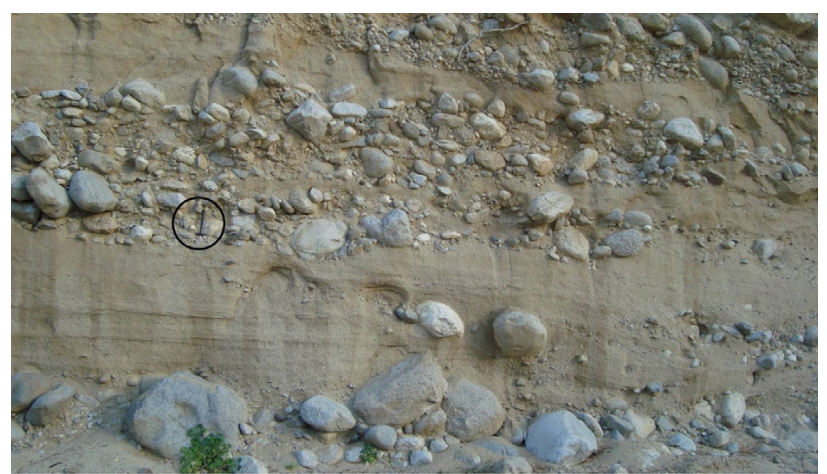

Figura 13. Arenisca conglomerádica y conglomerado de la Formación El Chorro sobre el arroyo San Dionisio (localidad 1). En el círculo negro, martillo de geólogo como escala de referencia.

\section{Evolución estratigráfica}

La CSJC es parte de la Provincia Extensional del Golfo (Stock y Hodges, 1989; Martín-Barajas, 2000; Fletcher et al., 2007) y tiene una estructura de medio graben (Martínez-Gutiérrez y Sethi, 1997). Fletcher et al. (2000) determinaron el inicio de la exhumación acelerada en el bloque de piso hace 12 - 10 ma., marcando el inicio del fallamiento en la cuenca, el cual estos autores relacionaron con la activación de la FSJC. Recientemente Busch et al. (2011) reconocieron varias fallas sepultadas a lo ancho de la cuenca y especularon que específicamente una falla por debajo de la localidad de Santiago (Figuras 1 y 2), la cual llamaron falla Santiago, pudo haberse formado antes de 
Tabla 2. Clasificación de facies y subfacies de la secuencia superior en el arroyo San Dionisio.

\begin{tabular}{|c|c|c|c|}
\hline & Facies / Subfacies & Descripción & Interpretación \\
\hline \multirow{10}{*}{ 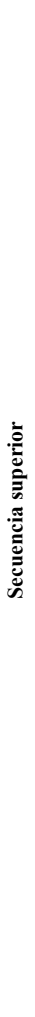 } & Facies EC1 & Orto- y paraconglomerado. & \\
\hline & $\begin{array}{l}\text { Subfacies EC1-a } \\
\text { Conglomerado }\end{array}$ & $\begin{array}{l}\text { Horizontes con espesores de hasta } 30 \mathrm{~cm} \text {. Tamaño de los clastos hasta } 10 \mathrm{~cm} \\
\text { comúnmente. }\end{array}$ & Depósitos tipo lag presentes en un sistema de abanico aluvial. \\
\hline & $\begin{array}{l}\text { Subfacies EC1-b } \\
\text { Conglomerado }\end{array}$ & $\begin{array}{l}\text { Lentes o agrupaciones de clastos gruesos, con espesores de hasta } 2 \mathrm{~m} \text {. En ocasiones } \\
\text { muestran formas de barras. }\end{array}$ & $\begin{array}{l}\text { Depósito mediante corrientes fluviales, formando lentes y/o } \\
\text { barras en abanicos aluviales. }\end{array}$ \\
\hline & $\begin{array}{l}\text { Subfacies EC1-c } \\
\text { Conglomerado }\end{array}$ & $\begin{array}{l}\text { Capas con espesores que alcanzan comúnmente } 1 \text { a } 2 \mathrm{~m} \text {, máximo } 7 \mathrm{~m} \text {. Soportado por } \\
\text { clastos o matriz. Tamaño de los clastos comúnmente hasta } 40 \mathrm{~cm} \text {. Arreglo interno } \\
\text { caótico, escasos clastos imbricados. Contactos erosivos, marcados o difusos. }\end{array}$ & $\begin{array}{l}\text { Flujos de escombro no cohesivos en ambiente de abanico } \\
\text { aluvial. }\end{array}$ \\
\hline & $\begin{array}{l}\text { Subfacies EC1-d } \\
\text { Conglomerado }\end{array}$ & $\begin{array}{l}\text { Depositado de manera cóncava o canalizada. El espesor alcanza } 7 \mathrm{~m} \text {. Soportado por } \\
\text { matriz principalmente. Tamaño común de los clastos hasta } 40 \mathrm{~cm} \text {. Arreglo interno } \\
\text { generalmente caótico, puede presentarse gradación normal. Contactos difusos. }\end{array}$ & $\begin{array}{l}\text { Depósitos canalizados a partir de flujos hiperconcentrados en } \\
\text { abanicos aluviales. }\end{array}$ \\
\hline & Facies EC2 & $\begin{array}{l}\text { Arenisca conglomerádica mal clasificada con gránulos. Clastos aislados de hasta } 30 \\
\mathrm{~cm} \text {. Estratificación paralela y cruzada. Poca bioturbación. }\end{array}$ & \\
\hline & $\begin{array}{l}\text { Subfacies } E C 2-a \\
\text { Arenisca conglomerádica }\end{array}$ & $\begin{array}{l}\text { Espesor de capas hasta } 17.50 \mathrm{~m} \text {. Arena mal clasificada y gránulos. Estratificación } \\
\text { paralela a cruzada plana de bajo ángulo y escala pequeña, ambas difíciles de } \\
\text { identificar debido a bioturbación. Contactos erosivos, marcados o difusos. }\end{array}$ & $\begin{array}{l}\text { Depósitos de flujos de avenida supercríticos asociados a } \\
\text { abanicos aluviales. }\end{array}$ \\
\hline & $\begin{array}{l}\text { Subfacies } E C 2-b \\
\text { Arenisca conglomerádica }\end{array}$ & $\begin{array}{l}\text { Espesor de capas hasta } 13.30 \mathrm{~m} \text {. Internamente diferenciada entre arenisca fina y más } \\
\text { gruesa hasta gránulos, alternando a una escala de pocos milímetros a centímetros. } \\
\text { Estratificación paralela marcada, poca estratificación cruzada. Contactos marcados o } \\
\text { erosivos. }\end{array}$ & $\begin{array}{l}\text { Flujos de avenida con cambios en las condiciones hidráulicas } \\
\text { en ambiente de abanico aluvial. La estratificación paralela } \\
\text { refleja depósitos de régimen de flujo superior. }\end{array}$ \\
\hline & $\begin{array}{l}\text { Subfacies EC2-c } \\
\text { Arenisca conglomerádica }\end{array}$ & $\begin{array}{l}\text { Espesor de capas hasta } 16 \mathrm{~m} \text {. Arena mal clasificada con gravilla y escasos clastos } \\
\text { aislados de mayor tamaño. La estratificación es paralela difusa a marcada, poca } \\
\text { estratificación cruzada plana de bajo ángulo. Contactos erosivos, transicionales, } \\
\text { difusos o marcados. }\end{array}$ & $\begin{array}{l}\text { Flujos de avenida energéticamente más variables que EC2-a y } \\
\text { b dentro de abanicos aluviales. }\end{array}$ \\
\hline & $\begin{array}{l}\text { Subfacies } E C 2-d \\
\text { Arenisca conglomerádica }\end{array}$ & $\begin{array}{l}\text { Espesor de capas hasta } 18.20 \mathrm{~m} \text {. Arena mal clasificada con variaciones repetitivas } \\
\text { verticales difusas entre arena fina y gruesa en un rango de } 10 \text { a } 30 \mathrm{~cm} \text {. Pocos clastos } \\
\text { aislados. Estratificación cruzada y poca estratificación paralela. Contactos erosivos o } \\
\text { difusos. }\end{array}$ & $\begin{array}{l}\text { Depósitos de barras transversales, laterales y/o longitudinales, } \\
\text { que ocurrieron bajo un ambiente de corrientes trenzadas en un } \\
\text { sistema de abanico aluvial. }\end{array}$ \\
\hline
\end{tabular}

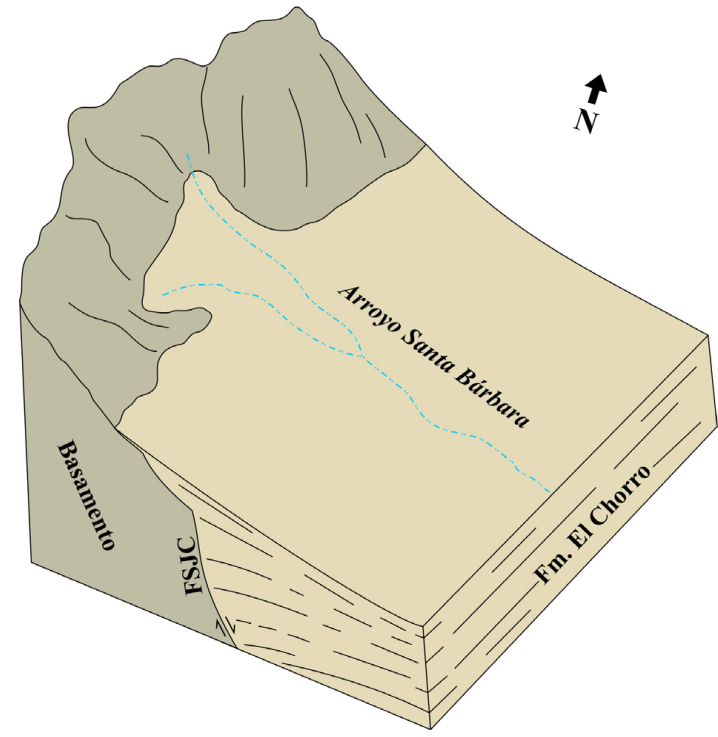

Figura 14. Depósitos de la Formación El Chorro cubriendo a la FSJC en la mesa Los Chorritos (Figura 2, localidad 14).

la FSJC. Esta falla Santiago marca un escalón de $\sim 500 \mathrm{~m}$ de altura en el contacto del basamento con el relleno de la cuenca, y entre esta falla y la FSJC la secuencia sedimentaria tiene un espesor máximo de $800 \mathrm{~m}$ aproximadamente (Busch et al., 2011: Figura 6). Para las fallas sepultadas propusieron una edad de Mioceno tardío y para la FSJC sugirieron una edad pliocénica. Aunque los resultados de Fletcher et al. (2000) y Busch et al. (2011) parecen contradictorios, es posible reconciliarlos ya que la supuesta activación de la falla Santiago en el Mioceno tardío, actuó inicialmente como falla marginal y pudo ser la causa para la exhumación de su bloque de piso (sierra La Victoria). Posteriormente, la activación de la FSJC aceleró esta exhumación.

En la etapa inicial de la cuenca se formaron abanicos aluviales (Martínez-Gutiérrez y Sethi, 1997). Los depósitos más antiguos de este ambiente (Formación Calera) se encuentran en el este de la cuenca y tienen una edad de Mioceno tardío (McTeague, 2006). La transgresión marina durante el Mioceno tardío limitó los abanicos con sedimentación terrestre a las márgenes de la cuenca; los primeros registros de interdigitación entre depósitos marinos y terrestres se encuentran en la porción oriental de la misma (McTeague, 2006; Schwennicke y Umhoefer, 2008) y para el Plioceno, en el oeste de la cuenca (Arreguín-Rodríguez, 2010). En el área de estudio en el arroyo San Dionisio esta interdigitación corresponde a las formaciones Los Barriles y Trinidad (Figura 15a). Debido al gradiente diferente desde las áreas circundantes hacia la cuenca durante el depósito, los sedimentos de los abanicos varían de dominantemente arenosos (Formación Calera) a gravosos (Formación Los 
Barriles). La diferencia en el gradiente se debe a la estructura de medio graben de la cuenca.

El modelo de evolución estratigráfica para el área del arroyo San Dionisio y sus alrededores, que se propone a continuación, consiste en varias etapas (Figura 15). Los depósitos de la unidad inferior en la margen occidental de la cuenca San José del Cabo reflejan un conjunto de ambientes sedimentarios, abarcando abanico aluvial con transición hacia depósitos marinos formados por encima y por debajo del nivel base de oleaje. Esta transición corresponde a un abanico deltaico tipo Gilbert sin presencia de grupos de capas frontales (foresets beds). La unidad inferior no aflora adyacente a la FSJC; sin embargo, se supone su existencia en el subsuelo. El perfil gravimétrico de Busch et al. (2011), con orientación NW-SE en la cuenca, atraviesa la mesa Los Chorritos al sur del arroyo San Dionisio. En la parte central de esta mesa el espesor de toda la secuencia sedimentaria alcanza aproximadamente $800 \mathrm{~m}$ (Busch et al., 2011: Figura 6). Considerando la diferencia de altitud entre la mesa y el lecho del arroyo, se estima que el espesor sedimentario desde el lecho del arroyo hasta el basamento es de $700 \mathrm{~m}$. Se desconoce si esta secuencia pertenece por completo a la unidad inferior (formaciones Los Barriles y Trinidad) o si bien incluye otra unidad sedimentaria más abajo.

Debido a la falta de fósiles índice en la unidad inferior, no existen datos que pudieran indicar la edad de los depósitos en el arroyo San Dionisio y sus alrededores. La localidad más cercana es El Torote, ubicada al sureste del área de estudio (Figura 2), donde Ibaraki (1997) determinó una edad de Plioceno temprano con base en un estudio detallado de foraminíferos. Sin embargo, el estudio de radiolarios de Molina-Cruz (1994), sugiere una edad del Mioceno tardío. Carreño (1992) marcó un rango de edad, por lo menos, hasta la base del Plioceno tardío aunque no se sabe con certeza
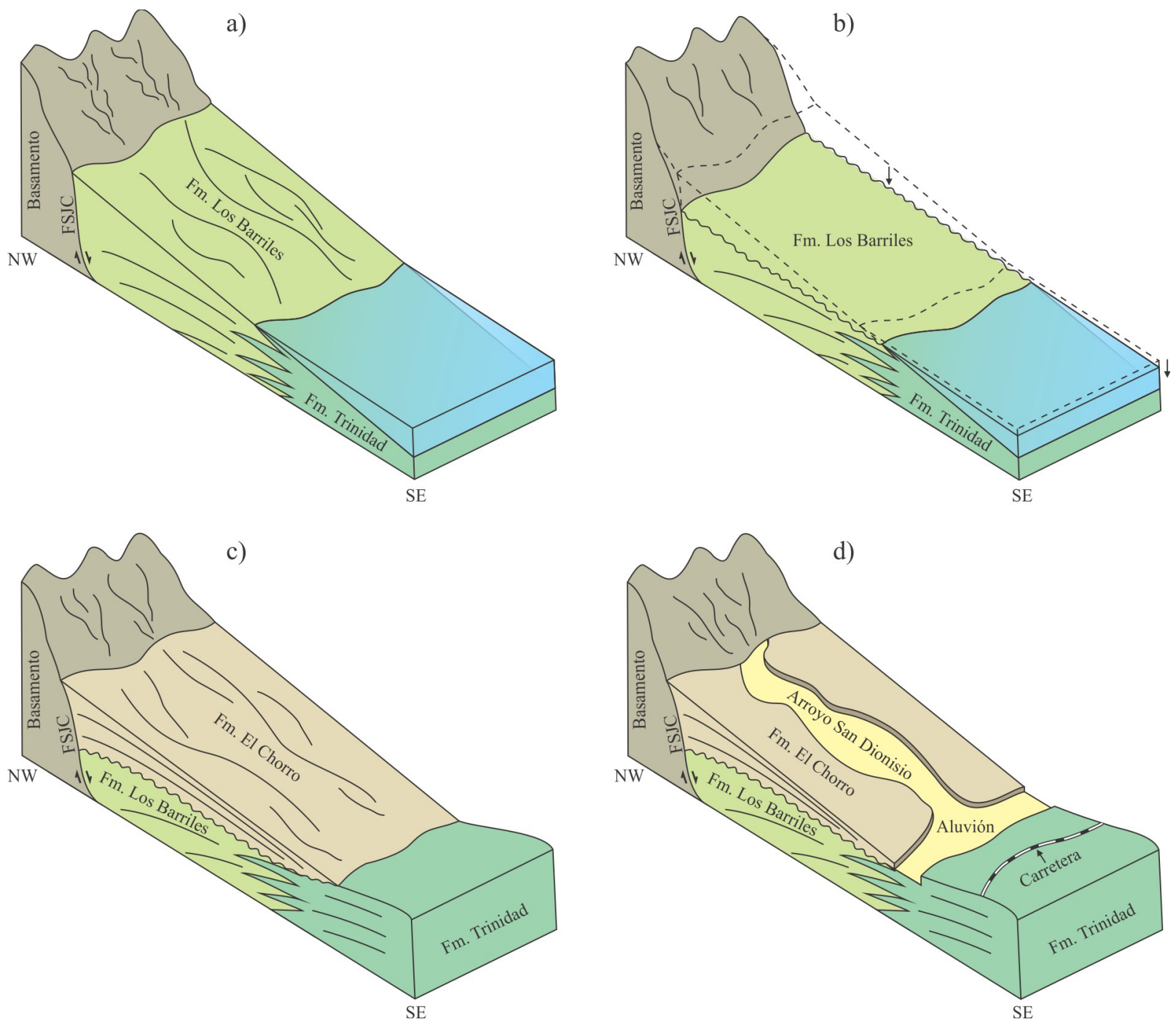

Figura 15.Modelo de evolución del área de estudio. a) Zona costera con abanicos deltaicos, resultando en la interdigitación entre las formaciones Los Barriles y Trinidad. b) Erosión de la unidad inferior. c) Formación del levantamiento estructural y topográfico en conjunto con el depósito de la Formación El Chorro. d) Los arroyos actuales cortaron el terreno, borrando las relaciones laterales entre las formaciones Trinidad y El Chorro. 
el origen de su columna, ya que la información dada en el trabajo sobre la localización de su columna es contradictoria y no coincide con la situación real en el campo. A pesar de ello, datos no publicados de Carreño señalan que las rocas más jóvenes de la Formación Trinidad corresponden al Plioceno temprano (comunicación personal Ana Luisa Carreño, 19 octubre 2012). Busch et al. (2011) sugirieron una edad pliocénica para las capas en la región alrededor de Santiago, tomando en cuenta la inclinación general de los estratos en la cuenca. Considerando lo anterior, se estima una edad de Plioceno temprano hasta posiblemente tardío para la unidad inferior a lo largo del arroyo San Dionisio (formaciones Los Barriles y Trinidad).

La segunda etapa representa el periodo de erosión de la Formación Los Barriles. Este evento refleja un descenso relativo del nivel base para el sistema fluvial (Figura 15b). Es probable que este cambio en el nivel base haya sido consecuencia de un levantamiento del terreno y pudo haber ocurrido por la activación de una falla normal al este del arroyo San Dionisio o bien por un levantamiento general de la región.

El desconocimiento de la edad de la Formación Trinidad en el arroyo San Dionisio impide que se conozca el momento en que se formó la discordancia erosiva. Por lo tanto, se puede considerar tres escenarios para el origen de dicha discordancia: 1) Que la erosión haya ocurrido durante el depósito de la Formación Trinidad, de manera que la erosión estuviera limitada solamente en la parte marginal de la cuenca (junto a la falla San José del Cabo), y que la sedimentación de la Formación Trinidad continuara hacia la parte central de la cuenca, rellenando el espacio de acumulación disponible. Esto implicaría que el depósito de la Formación Trinidad haya durado más tiempo en el centro de la cuenca San José del Cabo, en comparación con su margen oeste. Esta idea es apoyada por el hecho de que en las rocas marinas de la Formación Trinidad, al este del arroyo San Dionisio, no se observa un contacto erosivo o evidencia de una regresión forzada. Por otro lado, en la parte central de la cuenca se observa que la Formación El Chorro sobreyace discordantemente a la Formación Refugio, la cual es más joven que la Formación Trinidad (MartínezGutiérrez y Sethi, 1997). 2) Que la discordancia se haya dado después que terminó el depósito de la Formación Trinidad, incluso en la parte central de la cuenca, y que la primera parte del hiatus en la región marginal corresponda en tiempo a los depósitos costeros gruesos de la Formación Refugio (ver Marco geológico, Figura 1). Posteriormente el régimen erosivo se extendió también hacia la parte central de la cuenca. 3) O bien, que tal discordancia erosiva en toda la cuenca sea todavía más joven que la Formación Refugio. De los tres escenarios anteriores, el primero parece ser el menos probable debido a la existencia del contacto discordante entre las formaciones El Chorro y Refugio en el centro de la cuenca.

Posteriormente, por reactivación de la falla San José del Cabo, se creó un nuevo espacio de acumulación donde se depositó la Formación El Chorro, la cual tiene su mayor espesor junto a la FSJC, y hacia el este su espesor se reduce debido a la rotación de las rocas anteriores a la Formación El Chorro. En consecuencia, en la región al este del arroyo San Dionisio, las rocas anteriores a la Formación El Chorro quedaron más elevadas, semejante a lo observado por Geoffroy y Pronost (2009) al noroeste de Buena Vista (Figura 1). La evidencia para la rotación es la inclinación que presenta la discordancia. Es poco probable que la Formación El Chorro haya cubierto originalmente el área de la Carretera Federal No.1, ya que el borde oriental de la mesa Los Chorritos, cuya superficie corresponde a la superficie sedimentaria al término del depósito de la Formación El Chorro, en lugar de ser más elevado, está casi $100 \mathrm{~m}$ más bajo que la carretera (Figura 2). Por lo tanto, los depósitos de la Formación El Chorro debieron acuñarse en lo que actualmente es la unión de los arroyos San Dionisio y Santiago (Figuras 2 y 15c). No se sabe la edad del inicio del depósito de esta unidad puesto que se desconoce la duración del hiatus entre las formaciones Los Barriles y El Chorro. Considerando que en la localidad 43 (El Torote) la Formación El Chorro sobreyace a la Formación Trinidad (Plioceno temprano; Ibaraki, 1997), el depósito de la Formación El Chorro probablemente inició en el Plioceno tardío o Pleistoceno temprano. Se estima que su acumulación terminó en el Pleistoceno (Gibbard et al., 2010). En la mesa Los Chorritos, el contacto entre la Formación El Chorro y el basamento es irregular y no corresponde a la posición de la FSJC (Figura 2, localidad 14). Se concluye que durante el depósito de la última parte de la Formación El Chorro, la actividad de la FSJC fue mínima o nula, por lo que los sedimentos cubrieron a la falla como consecuencia de la erosión retrograda (Figuras 2 y 14, localidad 14). Desde finales del Pleistoceno hasta la actualidad, los arroyos actuales disectaron el relleno de la cuenca, erosionando una parte de la Formación El Chorro y borrando las relaciones entre esta unidad y la Formación Trinidad (Figura 15d).

\section{Discusión y conclusiones}

El presente estudio contribuye al conocimiento sobre las relaciones estratigráficas en el área del arroyo San Dionisio, ubicado en la margen occidental de la cuenca San José del Cabo. En los últimos años se ha estudiado la arquitectura de facies a lo largo de la margen oriental de la cuenca (McTeague, 2006; Schwennicke y Umhoefer, 2008; Piña-Arce, 2010), ampliando la información presentada por Martínez-Gutiérrez y Sethi (1997). Estos trabajos confirman que los sedimentos más antiguos en la cuenca afloran a lo largo de su margen oriental y a su vez revelan la complejidad de las relaciones de facies en esta área, especialmente en relación con el desarrollo de abanicos deltaicos tipo Gilbert con grupos de capas frontales (foresets beds). El presente trabajo señala que el área de San Dionisio no muestra el 
mismo grado de complejidad estructural y de facies que la margen oriental de la cuenca; sin embargo, se observa la contemporaneidad de unidades y variaciones de los ambientes de depósito, incluyendo abanicos aluviales y abanicos deltaicos. De modo que en ambas márgenes de la cuenca San José del Cabo se desarrollaron abanicos deltaicos como ocurre típicamente en las cuencas de rift (Gawthorpe y Leeder, 2000), aunque de tipos diferentes. Los abanicos deltaicos tipo Gilbert de la margen oriental de la cuenca (Schwennicke y Umhoefer, 2008) al parecer avanzaron progresivamente hacia aguas relativamente profundas (McTeague, 2006). En el área del arroyo San Dionisio, como parte de la margen occidental de la cuenca, se observa la interdigitación de depósitos aluviales y marinos. Esta interdigitación se reconoce como un abanico deltaico, sin clinoformas. En general, a lo largo de fallas maestras pueden formarse abanicos deltaicos tipo Gilbert en etapas de mayor subsidencia (Dorsey et al., 1995; Mortimer et al., 2005; García-García et al., 2006). Por otro lado, los abanicos deltaicos sin grupos de capas frontales (foreset beds), de aguas somera, pueden desarrollarse ya sea en una posición alejada de la falla maestra, o bien, cerca o encima de una estructura roll-over generada por la rotación a lo largo de la falla maestra (García-García et al., 2006). En el área de estudio, la interdigitación entre los depósitos de abanico aluvial-abanico deltaico ocurre aproximadamente a $7 \mathrm{~km}$ de la falla, es decir en un área alejada de la zona de mayor subsidencia y rotación por la falla. Ahora bien, aunque Geoffroy y Pronost (2009) reconocieron una estructura rollover en la región al noroeste de Buena Vista, en el arroyo San Dionisio al parecer no existe una estructura roll-over; sin embargo, la rotación del bloque de techo a lo largo de la falla sí causó que las capas más distantes (al este) quedaran más elevadas. Al haber un espacio de acumulación más reducido en esta área, en comparación con la zona más proximal a la falla, no se desarrollaron grupos de capas frontales (foresets beds) (García-García et al., 2006).

En el presente estudio se encontró que las formaciones Los Barriles y Trinidad, por lo menos en el arroyo San Dionisio, son contemporáneas, evidenciado por la interdigitación entre ellas. Ésto refleja la existencia de una zona costera con abanicos deltaicos. Lo anterior modifica la idea de Martínez-Gutiérrez y Sethi (1997) de que la Formación Los Barriles cubre a la Formación Trinidad y además se interdigite con la Formación Refugio. Nuestros resultados y de otros autores (McTeague, 2006; Schwennicke y Umhoefer, 2008) dejan ver que durante el depósito de los sedimentos marinos de la Formación Trinidad se desarrollaron abanicos deltaicos en ambas márgenes de la CSJC, con sedimentos predominantemente conglomerádicos del lado occidental (arroyo San Dionisio) y conglomerádicos hasta arenosos en la margen oriental. Estas relaciones reflejan una situación típica en cuencas de rift (Gawthorpe y Leeder, 2000).

El conocimiento deficiente sobre la edad de la Formación Trinidad en las diversas localidades hace difícil comparar el área de estudio con el lado este de la cuenca de San José del Cabo. Sin embargo, una edad pliocénica parece probable en el área del arroyo San Dionisio, según datos bioestratigráficos de El Torote, como la localidad más cercana con un fechamiento confiable y por la inclinación general de los estratos. A su vez, la falta de datos sobre la edad dificulta relacionar los cambios tectónicos locales (hiatus entre las formaciones Los Barriles y El Chorro) con posibles eventos regionales. Hace 5 - 6 ma. en la región sur del golfo de California inició el cambio de un régimen de extensión ortogonal hacia uno transtensional (Fletcher y Munguía, 2000) y el primer fondo marino basáltico fue producido hace 3.6 ma. (DeMets et al., 1987; DeMets, 1995). En las diversas cuencas en la región sur de la Provincia Extensional del Golfo (cuenca Punta Colorada en la isla San José, cuenca Perico en la isla del Carmen, cuenca de Loreto) no existe coincidencia temporal en la subsidencia y su posterior levantamiento. En la cuenca Punta Colorada, en la isla San José, la mayor subsidencia ocurrió alrededor de 2.5 - 2.4 ma. (Umhoefer et al., 2007), en la cuenca Perico en la isla del Carmen la mayor subsidencia tiene una edad entre 3.5 - 3.1 ma. (Dorsey et al., 2001) y en la cuenca de Loreto la subsidencia ocurrió entre 2.6 - 2.0 ma. (Dorsey y Umhoefer, 2000). En la cuenca San José del Cabo la mayor subsidencia ocurrió más temprano que en las cuencas mencionadas anteriormente, probablemente en el Mioceno tardío a Plioceno temprano (Molina-Cruz, 1994; Ibaraki, 1997; Martínez-Gutiérrez y Sethi, 1997; McTeague, 2006; Carreño y Smith, 2007). El hiatus entre las formaciones Los Barriles y El Chorro indica que hubo una etapa de erosión relacionada con un descenso relativo del nivel base.

El rango de edad sugerido por Martínez-Gutiérrez y Sethi (1997) para el depósito de la Formación El Chorro, Pleistoceno Tardío a Holoceno temprano, parece poco factible ya que implicaría la creación de toda la red de drenaje actual durante el resto del Holoceno. Por lo tanto, se propone que el depósito de dicha formación haya iniciado probablemente en el Plioceno tardío y terminado durante el Pleistoceno (límite Plioceno-Pleistoceno: 2.58 ma., Gibbard et al., 2010). Durante el depósito de la parte más joven de la Formación El Chorro, la FSJC disminuyó drásticamente su actividad o quedó inactiva y en consecuencia los depósitos cubrieron a la falla. Lo anterior revela que la FSJC ha estado muy poco activa o inactiva desde finales del Pleistoceno.

\section{Referencias}

Arreguín-Rodríguez, G.J., 2010, Evolución estratigráfica en el margen occidental de la Cuenca San José del Cabo, arroyo San Dionisio, Baja California Sur: La Paz, México, Universidad Autónoma de Baja California Sur, tesis de licenciatura, 67 p.

Busch, M.M., Arrowsmith, J.R., Umhoefer, P.J., Coyan, J.A., Maloney, S.J., Martínez-Gutiérrez, G., 2011, Geometry and evolution of riftmargin, normal-fault-bounded basins from gravity and geology, La Paz - Los Cabos region, Baja California Sur, Mexico: Lithosphere, 3(2), 110-127. 
Carreño, A.L., 1992, Neogene microfossils from the Santiago Diatomite, Baja California Sur, Mexico, en Calcareous Neogene microfossils of Baja California Sur, Mexico: Universidad Nacional Autónoma de México, Instituto de Geología, Paleontología Mexicana, 59(1), 1-37.

Carreño, A.L., Segura-Vernis, L.R., 1991, Ostrácodos de la Formación Trinidad, Baja California Sur, México, en Carrillo-Chávez, A., Álvarez-Arellano, A. (eds.), Memorias de la Primera Reunión Internacional sobre Geología de la Península de Baja California: La Paz, Sociedad Geológica Peninsular, Universidad Autónoma de Baja California Sur, 101-110.

Carreño, A.L., Smith, J.T., 2007, Stratigraphy and correlation for the ancient Gulf of California and Baja California Peninsula, Mexico: Bulletin of American Paleontology, 371, 97-104.

DeMets, C., Gordon, R.G., Stein, S., Argus, D.F., 1987, A revised estimate of Pacific-North American plate motion and implications for western North American plate boundary zone tectonics: Geophysical Research Letters, 14, 911-915.

DeMets, C., 1995, A reappraisal of seafloor spreading lineations in the Gulf of California: Implications for the transfer of Baja California to the Pacific Plate and estimates of Pacific North America Motion: Geophysical Research Letters, 22(24), 3545-3548.

Dorsey, R.J., Umhoefer, P.J., 2000, Tectonic and eustatic controls on sequence stratigraphy of the Pliocene Loreto basin, Baja California Sur, Mexico: Geological Society of America Bulletin, 112(2), 177-199.

Dorsey, R.J., Umhoefer, P.J., Renne, P.R., 1995, Rapid subsidence and stacked Gilbert-type fan deltas, Pliocene Loreto basin, Baja California Sur, Mexico: Sedimentary Geology, 98,181-204.

Dorsey, R.J., Umhoefer, P.J., Falk, P.D., 1997, Earthquake clustering inferred from Pliocene Gilbert-type fan deltas in the Loreto basin, Baja California Sur, Mexico: Geology, 25, 679-682.

Dorsey, R.J., Umhoefer, P.J., Ingle, J.C., Mayer, L., 2001, Late Miocene to Pliocene stratigraphic evolution of northeast Carmen Island, Gulf of California: implications for oblique-rifting tectonics: Sedimentary Geology, 144, 97-123.

Einsele, G., Seilacher, A., 1991, Distinction of tempestites and turbidites, en Einsele, G., Ricken, W., Seilacher, A. (eds.), Cycles and events in stratification. Berlin, Springer, 377-382.

Field, M.E., Gardner, J.V., Jennings, A.E., Edwards, B.D., 1982, Earthquake induced sediment failures on a $0.25^{\circ}$ slope, Klamath River delta, California: Geology, 10, 542-546.

Fletcher, J.M., Munguía, L., 2000, Active continental rifling in southern Baja California, Mexico: Implications for plate motion partitioning and the transition to seafloor spreading in the Gulf of California: Tectonics, 19(6), 1107-1123.

Fletcher, J.M., Grove, M., Kimbrough, D., Lovera, O., Gehrels, G.E., 2007, Ridge-trench interactions and the Neogene tectonic evolution of Magdalena shelf and southern Gulf of California: Insights from detrital zircon $\mathrm{U}-\mathrm{Pb}$ ages from the Magdalena fan and adjacent areas: Geological Society of America Bulletin, 119(11/12), 1313-1336.

Gaitán-Morán, J., 1985, On Neotectonic evidence in the southern peninsular region, Baja California Sur, Mexico: International Institute for Aerospace Survey and Earth Science ITC Journal, 1985(4), 293-294.

García-García, F., Fernández, J., Viseras, C., Soria, J.M., 2006, Architecture and sedimentary facies evolution in a delta stack controlled by fault growth (Betic Cordillera, southern Spain, late Tortonian): Sedimentary Geology, 185, 79-92.

Gawthorpe, R.L., Leeder, M.R., 2000, Tectono-sedimentary evolution of active extensional basins: Basin Research, 12, 195-218.

Geoffroy, L., Pronost, J., 2009, Late Pliocene to Early Quaternary extensional detachment in the La Paz-El Cabo area (Baja California Sur, Mexico): implications on the opening of the Gulf of California and the mechanics of oblique rifting: Terra Nova, 22, 64-69.

Gibbard, P.L., Head, M.J., Walker, M.J.C., The Subcommission on Quaternary Stratigraphy, 2010, Formal ratification of the Quaternary System/Period and the Pleistocene Series/Epoch with a base at 2.58 Ma: Journal of Quaternary Science, 25(2), 96-102.

Gibert, L., Sanz de Galdeano, C., Alfaro, P., Scott, G., López-Garrido,
A.C., 2005, Seismic-induced slump in Early Pleistocene deltaic deposits of the Baza Basin (SE Spain): Sedimentary Geology, 179(3-4), 279-294.

Hertlein, L.G., 1925, Pectens from the Tertiary of Lower California, California: Proceedings of the Academy of Science, 14(1), 1-35.

Hertlein, L.G., Jordan, E. K., 1927, Paleontology of the Miocene of Lower California: California Academy of Science Proceedings, 16(19), 605-647.

Ibaraki, M., 1997, Planktonic Foraminifera from the Trinidad Formation in Baja California and their paleoceanographic implications: Reports of the Faculty of Science, Universidad de Shizuoka, 31, 35-43.

Lewis, K.B., 1971, Slumping on a continental slope inclined at $1^{\circ}-4^{\circ}$ : Sedimentology, 16, 97-110.

Martín-Barajas, A., 2000, Volcanismo y extensión de la Provincia Extensional del Golfo de California: Boletín de la Sociedad Geológica Mexicana, 53, 72-83.

Martínez-Gutiérrez, G., Sethi, P.S., 1997, Miocene-Pleistocene sediments within the San José del Cabo Basin, Baja California Sur, Mexico, en Johnson, M.E., Ledesma-Vázquez, J., (eds.), Pliocene carbonates and related facies flanking the Gulf of California, Baja California, Mexico: Geological Society of America Special Paper, 318, 141-166.

Masini, E., Robin, C., Geoffroy, L., Strzerzynski, P., 2010, The supradetachment tectono-sedimentary record of rifted margins: the example of the Los Barriles Basin, SE Baja California Sur (resumen), en EGU General Assembly 2010, Geophysical Research Abstracts, 12, EGU2010-12049.

McCloy, C., 1984, Stratigraphy and depositional history of the San Jose del Cabo trough, Baja California Sur, Mexico, en Frizzell, V. A. Jr., (ed.), Geology of the Baja California peninsula: Society of Economic Paleontologists and Mineralogists, Pacific Section, 39, 267-273.

McTeague, M.S., 2006, Marginal strata of the east central San Jose del Cabo basin, Baja California, Mexico: Northern Arizona University, tesis de maestría, $152 \mathrm{p}$.

McTeague, M.S., Umhoefer, P.J., Schwennicke, T., Ingle, J., 2005, Sedimentary record of Miocene rifting along the eastern side of the San Jose del Cabo Basin, Baja California Sur, Mexico: critical early evidence of the proto Gulf of California, en Salt Lake City Annual Metting, Geological Society of America, 37(7), $311 \mathrm{p}$.

Mina-Uhink, F., 1957, Bosquejo geológico del territorio sur de la Baja California: Boletín de la Asociación Mexicana de Geólogos Petroleros, 9, 139-270.

Molina-Cruz, A., 1994, Bioestratigrafía y significado paleoceanográfico de los radiolarios de la protoboca del Golfo de California: Ciencias Marinas, 20(4), 441-465.

Mortimer, E., Gupta, S., Cowie, P., 2005, Clinoform nucleation and growth in coarse-grained deltas, Loreto basin, Baja California Sur, Mexico: a response to episodic accelerations in fault displacement: Basin Research, 17, 337-359.

Myrow, P.M., Southard, J.B., 1996, Tempestite deposition: Journal of Sedimentary Research, 66(5), 875-887.

Niemi, T.M., Ben-Avraham, Z., 1994, Evidence for Jericho earthquakes from slumped sediments of the Jordan River delta in the Dead Sea: Geology, 22, 395-398.

Pantoja-Alor, J., Carrillo-Bravo, J., 1966, Bosquejo de la región de Santiago - San José del Cabo, Baja California: Boletín de la Asociación Mexicana de Geólogos Petroleros, 58, 1-14.

Pérez-Guzmán, A.M., 1985, Radiolarian bioestratigraphy of the late Miocene in Baja California and the Tres Marías Island, Mexico: Micropaleontology, 31(4), 320-334.

Pérez-López, O.G., 2002, Caracterización paleontológica de bivalvos y gasterópodos (Mollusca), en cinco localidades de la Formación Refugio (Plioceno), Baja California Sur, México: La Paz, México, Universidad Autónoma de Baja California Sur, tesis de licenciatura, $139 \mathrm{p}$.

Piña-Arce, M., 2010, Bioestratigrafía con nanofósiles calcáreos en el área del Rancho Los Algodones, Baja California Sur, México: La Paz, México, Universidad Autónoma de Baja California Sur, tesis de licenciatura, $60 \mathrm{p}$. 
Postma, G., 1990, Depositional architecture and facies of river and fan deltas: a synthesis: International Association of Sedimentologists Special Publication, 10, 13-27.

Rodríguez-Quintana, R., Segura-Vernis, L.R., 1991, Gasterópodos fósiles de la Formación Trinidad, Baja California Sur, en Carrillo-Chávez, A. y Álvarez-Arellano, A. (eds.), Memorias de la Primera Reunión Internacional sobre Geología de la Península de Baja California: La Paz, Sociedad Geológica Peninsular, Universidad Autónoma de Baja California Sur, 111-133.

Schwennicke, T., Umhoefer, P.J., 2008, Evolución tectonoestratigráfica a lo largo del margen oriental de la cuenca de San José del Cabo (resumen), en Primer congreso sobre la evolución geológica y ecológica del Noroeste de México, Hermosillo, Sonora, 107.

Smith, J.T., 1991, Cenozoic marine mollusks and paleogeography of the Gulf of California, en Dauphin, J., Simoneit, B., (eds.), The Gulf and Peninsular Province of the Californias: American Association of Petroleum Geologists Memoir, 47, 637-666.

Stock, J.M., Hodges, K.V., 1989, Pre-Pliocene extension around the Gulf of California and the transfer of Baja California to the Pacific plate: Tectonics, 8, 99-115.
Trápaga-Martínez, R., 1985, Estudio bioestratigráfico e interpretación paleoceanográfica con radiolarios del Mioceno en Diatomita Santiago y Rancho La Ventana, Baja California Sur, México: México, Universidad Nacional Autónoma de México, tesis de licenciatura, $106 \mathrm{p}$.

Umhoefer, P.J., Schwennicke, T., Del Margo, M. T., Ruiz-Geraldo, G., Ingle, J. C., McIntosh, W., 2007, Transtensional fault-termination basins: an important basin type illustrated by the Pliocene San Jose Island basin and related basins in the southern Gulf of California, Mexico: Basin Research, 19(2), 297-322.

Xu, G., Sun, Y., Wang, X., Hu, G., Song, Y., 2009, Wave-induced shallow slides and their features on the subaqueous Yellow River delta: Canadian Geotechnical Journal, 46, 1406-1417.

Manuscrito recibido: Julio 11, 2012.

Manuscrito corregido recibido: Enero 23, 2013.

Manuscrito aceptado: Enero 30, 2013. 